\title{
Exploring Cytotoxic Potential of Ciclopirox on Colorectal Cancer Cells by In-Silico Methodology
}

\author{
Savita Shrikant Deokar ${ }^{1}$ (D), Karimunnisa Sameer Shaikh 2,* (D) \\ 1 PES's Modern College of Pharmacy, Nigdi, Pune, Maharashtra, India; savitadeokar1979@gmail.com (S.S.D.); \\ 2 PES's Modern College of Pharmacy, Nigdi, Pune, Maharashtra, India; karima78@ rediffmail.com (K.S.S.); \\ * Correspondence: karima78@ rediffmail.com (K.S.S.);
}

Scopus Author ID 36627715700

Received: 29.09.2021; Revised: 1.11.2021; Accepted: 4.11.2021; Published: 24.11.2021

\begin{abstract}
Colorectal cancer (CRC) stands $3^{\text {rd }}$ among male cancer cases and the second most prevalent disease in women, accounting for $10 \%$ of all cancer cases globally. Ciclopirox (CPX) is a broadspectrum, synthetic, off-patent antifungal drug recommended in dermatological conditions of mycoses of the skin and nails. There are no important molecular docking studies on inhibitory aspects of CPX against CRC targets. The main objective of this study was to explore the potential of CPX as an antiCRC agent by using in-silico approaches with the help of published literature on downregulation of overhead protein expression in CRC and combining this information in order to recognize novel drug targets [Cell division cycle 25A (Cdc25A), Protein deglycase DJ-1 (DJ-1), Retinoblastoma protein (p$\mathrm{Rb} / \mathrm{Rb}$ ), Cyclin-dependent kinase-4 (CDK4), High-mobility group AT-hook-2 (HMGA2), and Catenin $\beta-1$ (Wnt/-catenin)] and to identify the perspectives for drug repurposing and comparing this with oxaliplatin; one of the standard drug used in CRC. Also, in silico drug-likeliness studies, bioavailability studies, pharmacokinetic studies, drug target prediction, and bioisosteric replacement have been performed for CPX using online SwissADME tools (SwissADME, SwissTargetPrediction, and SwissBioisostere). The in silico studies revealed that CPX successfully inhibited all the molecular targets, which suggested plausible re-utilization of CPX for treating CRC.
\end{abstract}

Keywords: colorectal cancer; ciclopirox; molecular docking; pharmacokinetics; in silico; drug repurposing.

(c) 2021 by the authors. This article is an open-access article distributed under the terms and conditions of the Creative Commons Attribution (CC BY) license (https://creativecommons.org/licenses/by/4.0/).

\section{Introduction}

Colorectal cancer $(\mathrm{CRC})$ stands $3^{\text {rd }}$ among cancer cases in males and the second most prevalent disease in women, accounting for $10 \%$ of all cancer cases globally. Males have a25\% greater infection rate than females, but this varies by country [1]. With over 600,000 fatalities recorded each year, CRC is the fourth most frequent cancer-related cause of death globally. Colon and rectal cancer annual incidence rates among males in India are 4.4 and 4.1 per 100000, respectively [2]. In 2018, there were 1.8 million new CRC cases, with 881,000 fatalities, accounting for almost $10 \%$ of all new cancer cases and deaths globally, with the number of new cases projected to reach nearly 2.5 million by 2035 [3].

Colon cancer is caused by abnormal cell division and development in the colon. Polyps are benign or malignant growths that develop when cells divide abnormally. The precise reason for these atypical divisions is yet unknown. Ethnicity, age, family history, and a sedentary lifestyle, on the other hand, have been related to risk variables [4]. CRC is more prevalent among individuals over 50, African-Americans, and those who smoke a lot of cigarettes, drink 
much alcohol and consume much fat. People with a history of health issues, such as obesity or diabetes, are more susceptible to cancer [5]. Hereditary factors, on the other hand, account for about a fifth of all CRC cases. The two most prevalent forms of hereditary non-polyposis colon cancer are hereditary non-polyposis colon cancer (HNPCC, Lynch syndrome) and familial adenomatous polyposis coli (FAP) [6].

$\mathrm{CRC}$, like other cancers, has no symptoms in the early stages, making it difficult to diagnose. Symptoms include changes in stool frequency, rectal bleeding, stomach aches, tiredness, and weight loss. CRC may be diagnosed using sigmoidoscopy or colonoscopy, and treatment options include surgery, radiation therapy, and drug treatments including chemotherapy, targeted therapy, and immunotherapy [7]. Cytotoxic agents used in CRC include capecitabine, fluorouracil, irinotecan, oxaliplatin, and trifluridine/tipiracil. Nausea, diarrhea, neuropathy, and mouth sores are common side effects of chemotherapy and other medicines, as are more severe side effects including patient tiredness, increased infection risk, and more [8]. Neuropathy, or tingling or numbness in the feet or hands, is a side effect of certain medicines. Significant hair loss is an uncommon adverse effect of many of the medicines used to treat colorectal cancer, with the exception of irinotecan [9]. Targeted antibodies including Bevacizumab, Cetuximab, Panitumumab, Ramucirumab, and checkpoint inhibitors like Pembrolizumab, Nivolumab, and Nivolumab, and ipilimumab show the most common side effects including fatigue, rash, diarrhea, nausea, fever, muscle pain, bone pain, joint pain, abdominal pain, itching, vomiting, cough, decreased appetite and shortness of breath and serious side effects like infusion reactions, autoimmune reactions, etc. [10].

In this setting, there is a need for newer molecules that might have fewer side effects and higher efficiency. Ciclopirox (CPX) [6-cyclohexyl-1-hydroxy-4-methyl-2(1H)-pyridone] is a broad-spectrum, synthetic, off-patent antifungal drug that is recommended in dermatological conditions of mycoses of the skin and nails. It is used as a topical antifungal agent and comes in various forms, including gels, creams, lacquers, topical solutions, and shampoos [11]. CPX has a sole benefit over all other oral antimycotic agents, specifically in terms of benefit/risk ratio owing to its brilliant tolerability and absolute absence of severe adverse effects [12]. CPX has recently been discovered to have a lot of potential efficacy against various illnesses, including cancer, and has a strong anti-proliferative impact on tumor cells, which is exciting [24]. It has recently shown antitumor efficacy in vitro and in vivo and is undergoing a Phase-I trial for exploration in patients with relapsed hematologic malignancies or refractory hematologic malignancies [13]. However, in the field of CRC, especially the molecular targets, little attention has been paid so far with respect to the application of CPX. There are no important molecular docking studies on inhibitory aspects of CPX in the available literature. Hence, this study was undertaken to explore the potential of CPX as an anticolorectal cancer agent by the in-silico method.

Cell division cycle 25A (Cdc25A) is responsible for the proliferation and promotion of apoptosis of breast cancer, human rhabdomyosarcoma, Rh30; and colon adenocarcinoma. It is one of the most well-known targets of CRC. Cdc25A is required for cell cycle progression, and its activity must be carefully controlled. In rhabdomyosarcoma, Rh30, and breast cancer, MDA-MB-231 cells, increased Cdc25A phosphorylation or which accelerated protein degradation of Cdc25A is observed. As a result of the decreased Cdc25A protein level, the G1CDKs' inhibitory phosphorylation level is increased [14].

Another protein molecule, the High-mobility group AT-hook-2 (HMGA2), controls gene expression, DNA replication, and chromosomal repair, making it an appealing target for 
many kinds of cancer. HMGA2 impacts a number of biological processes, including DNA damage repair, apoptosis, cell cycle, and epithelial-mesenchymal transition. Overexpression of the HMGA2 protein has been linked to neoplastic transformation in a variety of malignancies, including $\mathrm{CRC}$, lung cancer, breast cancer, oral squamous cell carcinoma, and ovarian cancer [15].

Yet another protein important in CRC is protein deglycase (DJ-1). It is a highly conserved homodimeric protein that was first identified as an oncogene capable of transforming NIH-3T3 cells. DJ-1 is an endogenous antioxidant that protects cells from oxidative damage by influencing various signaling pathways, including apoptosis signalregulating kinase, extracellular signal-regulated kinase (ERK) 1/2, and apoptosis signalregulating kinase (ASK). DJ-1 overexpression increases CRC growth and spread [16].

A tumor suppressor, Retinoblastoma protein $(\mathrm{pRb})$, is a distinct target. It plays a key function in the negative regulation of the cell cycle and tumor development. $\mathrm{pRb}$ has been found to be involved in a key G1 checkpoint that prevents S-phase entrance and cell proliferation. Inhibition causes cell cycle arrest, repression of cell migration, and invasion in CRC by altering Snail, N-cadherin, MMP-2, E-cadherin, and MMP-9 expression and disrupting cellular bioenergetics, resulting in cell growth, migration, and invasion inhibition [17].

Cyclin-dependent kinases ( $\mathrm{p}-\mathrm{CDKs}$ ) are serine/threonine kinases that control the cell cycle by interacting with cyclin-like regulatory proteins. CDK-4 is a critical CDK cell cycle regulator that interacts with cyclin-D during the $G_{1}$ phase to regulate the transition from $G_{1}$ to the S phase. Many cancer types, including non-small cell lung cancer, colorectal carcinomas, melanomas, and breast cancer, show reduced levels of endogenous CDK inhibitors as well as CDK-4 overexpression. The importance of CDKs in cell cycle progression makes them prospective cancer therapeutic targets, and inhibitors of CDKs may be employed in selective chemotherapy [18].

Wingless-related integration sites (Wnts) are a family of autocrine and paracrine glycoproteins that have a role in mammary tissue development and cancer. Wnt proteins bind to the seven-transmembrane domain-containing Frizzled (FZD) receptor family, which subsequently heterodimerizes with a member of the low-density lipoprotein-related protein (LRP) family and activates disheveling, resulting in Wnt/catenin signaling. Disheveling blocks the capacity of constitutively active GSK3 to phosphorylate catenin, inhibiting its interaction with axin and therefore preventing the creation of destruction complexes. When unphosphorylated catenin binds to TCF4 in the nucleus, it creates a transcription complex that regulates the expression of target genes such as cyclin D1, c-myc, c-jun, and others. Because inhibitors of Wnts may stop cells from growing or proliferating, they might be exploited as a target for anticancer drugs [19].

The main objective of this study was to explore the potential of CPX as an anticolorectal cancer agent by using in-silico approaches. With the help of published literature on downregulation of overhead protein expression in CRC we sought to recognize novel drug targets [Cell division cycle 25A (Cdc25A), Protein deglycase DJ-1 (DJ-1), Retinoblastoma protein ( $\mathrm{p}-\mathrm{Rb} / \mathrm{Rb}$ ), Cyclin-dependent kinase-4 (p-CDK4), High-mobility group AT-hook-2 (HMGA2), and Catenin beta-1 (Wnt/-catenin)] to identify the perspectives for CPX repurposing in CRC. The results obtained were then compared with oxaliplatin (OPL), one of the standard drugs used in CRC. Moreover, the prediction of drug-likeliness, bioavailability, and pharmacokinetics of CPX has been performed using online computational tools (SwissADME, SwissTargetPrediction, and SwissBioisostere). 


\section{Materials and Methods}

\subsection{Preparation of ligand.}

The 3D structure of chosen ligand, Ciclopirox (PC CID: 2749) was obtained in ".sdf" format using PubChem (https://pubchem.ncbi.nlm.nih.gov/). PubChem is an open-access database of chemical substances and biological activity. The method addressed the docking issue using flexible ligands and moveable protein atoms. The Avogadro program was used to add hydrogen atoms to ligands. The MMFF94 force field is utilized to compute the energy of the proteinligand combination for every given configuration without any fitting parameters.

\subsection{Preparation of protein.}

Multiple 3D crystalline target structures were obtained from the Protein Data Bank (PDB) like Cell division cycle 25A (PDB ID: 1C25, Human CDC25A catalytic domain), Protein deglycase DJ-1 (Parkinson disease protein 7) (PDB ID: 3EZG, the Crystal structure of E18Q DJ-1 with oxidized C106), Retinoblastoma protein (PDB ID: 1N4M, Structure of Rb tumor suppressor bound to the transactivation domain of E2F-2), Cyclin-dependent kinase 4 (PDB ID: 3G33, the Crystal structure of CDK4/cyclin D3), High-mobility group AT-hook 2 (PDB ID: 3UXW, Crystal Structures of an A-T-hook/DNA complex), and Catenin beta-1 (PDB ID: 1JPW, Crystal Structure of a Human Tcf-4 / beta-Catenin Complex). The target was created by removing all water molecules beyond $5 \mathrm{~A}^{\circ}$, assigning disulfide links, bond order, and formal charges, and removing metal ions, co-factors, and hetero groups from the useable preprocessed and studied structure. With the assistance of the H-bond assignment technique, the hydrogen atoms and the hydrogen-bonding network were optimized. Molecular docking was used to estimate receptor grids for protein targets where the ligand would mix within the predicted active site. The grids (cubic boxes with defined dimensions) encompassed the whole ligand and were built at the ligand's centroid (crystallized with the target structure). The grid box size was increased to $126 \AA, 126 \AA$, and $126 \AA$ (x, y, and z, respectively) to embrace the majority number of the amino acid residues present in stiff macromolecules. Auto Grid 4.2, which came with Auto Dock 4.2, was used to generate grid maps. The grid points were $0.375^{\circ}$ apart. The Van der Waals scale factor was set to 1.0 , while the charge cutoff was set at 0.25 . Induced-fit docking (IFD) was conducted on each ligand, and the lowest resulting score for the best-docked posture was confirmed [20].

\subsection{Induced-fit molecular docking (IFD).}

The IFD was created utilizing the structure-based drug design technique, which involves rendering precise geometry ligands to dock with a biological target's defined structure. The free-state ligands are docked into the rigid state receptor's active site, enzyme, tube, etc., resulting in a predicted binding mode and the strength of the fit being evaluated. In receptorbased computational techniques, the attachment of a low-molecular-weight ligand to a macromolecular protein has its significance since the most suitable connection with low energy values and possible steric conflicts are found. To investigate a particular docking issue, Auto Dock provides a number of search methods. In this study, the Lamarckian Genetic Algorithm (LGA) was employed to identify the best conformers. During the docking process, a maximum of 10 conformers was evaluated. The population was limited to 150 individuals, who were selected at random. The mutation rate was set to 0.02 , and the crossover rate was set to 0.8 . 
The maximum number of energy evaluations was 500000 (default), generations were 1000 (default), top individuals that automatically survived was 1 (default). Translations had a 0.2 step size, quaternions had a $5.0^{\circ}$ step size, and torsions had a $5.0^{\circ}$ step size. Cluster tolerance was set to 0.5 , external grid energy to 1000.0 , maximum binding energy to 0.0 , the maximum number of retries to 10000 , and 10 LGA runs were performed. The interactions and binding energy of the docked structure were studied using the Auto Dock findings. It was performed many times to get different docked conformations as well as to assess anticipated docking energy. The optimal ligand-receptor structure was selected among the docked structures based on the ligand's lowest energy and minimum solvent accessibility. The Accelrys Visualizer discovery studio tool was used to visualize the docking findings [20].

\subsection{Pharmacokinetics, bioavailability, and drug-likeliness studies.}

The SwissADME online tool was used to conduct prediction research of pharmacokinetics, namely ADME, bioavailability, and drug-likeness of ligands. To identify drug-likeness, the technology estimates bioavailability radar based on six physicochemical properties: size, lipophilicity, insolubility, polarity, flexibility, and insaturation. The ADME properties, such as blood-brain barrier (BBB) permeation and passive human gastrointestinal absorption (HIA), as well as permeability glycoprotein (P-gp) substrate or non-substrate in the form of positive or negative, was detected through the BOILED-Egg model. The free energies of solvation in n-octanol and water calculated by the generalized-born and solvent accessible surface area (GB/SA) model, XLOGP3 is an atomistic method with corrective factors and a knowledge-based library, WLOGP is an implementation of a purely atomistic method, and MLOGP is an archetype of topological method rely on the lipophilicity estimation ( $\log \mathrm{p} / \mathrm{w})$ parameters such as iLOG The Lipinski (Pfizer) filter, which was the first rule-of-five to be implemented in a tool, was used to predict drug-likeness. The bioavailability radar was used to predict oral bioavailability based on several physicochemical characteristics. The ranges of each parameter was mentioned as SIZE = size as molecular weight $150 \mathrm{gm} / \mathrm{mol}<\mathrm{MV}<500$ $\mathrm{gm} / \mathrm{mol}$; LIPO = lipophilicity as $-0.7<\mathrm{XLOGP} 3<+5.0$; INSOLU $=$ insoluble in water by $\log$ $\mathrm{S}$ scale $0<\operatorname{Logs}(\mathrm{ESOL})<6$; POLAR = polarity as $20 \AA^{2}<\mathrm{TPSA}$ (topological polar surface area) $<130 \AA^{2} ;$ FLEX = flexibility as per rotatable bonds $0<$ Number of rotatable bonds < 9; and INSATU $=$ insaturation or saturation as per fraction of carbons in the $\mathrm{sp}^{3}$ hybridization 0.3 $<$ Fraction Csp3 < 1 [21].

\subsection{Drug target identifications.}

SwissTargetPrediction is a web service for small bioactive molecule target prediction. This website enables one to anticipate a tiny molecule's targets. It compares the query molecule to a library of 280,000 molecules active on more than 2000 targets in five distinct species using a mix of $2 \mathrm{D}$ and $3 \mathrm{D}$ similarity metrics. Understanding the molecular processes behind bioactivity and anticipating possible side effects or cross-reactivity requires mapping the targets of small bioactive compounds. Predictions have been made in three distinct organisms (models), and for near paralogs and orthologs, mapping predictions by homology within and across species is possible. The human (Homo sapiens), rat (Rattus norvegicus), and mouse (Mus musculus) models have all been shown to have credible inhibitory targets for CPX [22]. 
2.6. Core scaffold-based bioisosteric search.

The SwissBioisostere database offers data on molecular replacements and how well they function in biochemical tests. Its purpose is to provide researchers working on drug development projects suggestions for bioisosteric alterations to their existing lead molecule, as well as access to data on specific chemical replacements [23]. CPX's core scaffold was studied comprehensively through bioisosteric replacements to produce tetrahydropyran, piperidine, morpholine, and piperazine. The parameters affecting the biological target and associated activities were taken into account, and the derived data was interpreted.

\section{Results}

\subsection{Docking interaction analysis}

Table 1 shows binding energy, number of hydrogen bonds with distance, interaction residues, grid points spacing, and grid points $\mathrm{x}, \mathrm{y}, \mathrm{z}$ place.

Table 1. Interaction of ciclopirox against various anticancer targets of CRC.

\begin{tabular}{|c|c|c|c|c|c|c|}
\hline Protein Identifier & $\begin{array}{l}\text { Binding } \\
\text { Energy* }\end{array}$ & No. of $\mathrm{H}$ Bonds & $\begin{array}{l}\text { Interacting } \\
\text { residue }\end{array}$ & $\begin{array}{l}\text { GridPoint } \\
\text { Spacing }\end{array}$ & $\begin{array}{l}\text { Grid } \\
\text { Points }\end{array}$ & $\begin{array}{l}\text { Grid } \\
\text { Axes }\end{array}$ \\
\hline $\begin{array}{l}\text { Catenin beta-1 } \\
\qquad(1 \mathrm{JPW})\end{array}$ & -4.90 & $\begin{array}{c}01 \\
(\mathrm{H} 1: \text { Distance }= \\
2.07 \AA)\end{array}$ & GLN322(H1) & $1.000 \AA$ & $\begin{array}{c}50 x \\
100 y \\
70 z\end{array}$ & $\begin{array}{c}106.129,- \\
4.253, \\
18.577\end{array}$ \\
\hline $\begin{array}{l}\text { Cell division cycle } 25 \mathrm{~A} \\
(1 \mathrm{C} 25)\end{array}$ & -4.96 & 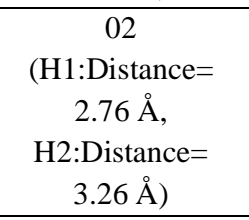 & $\begin{array}{c}\text { ASP:339(H1),L } \\
\text { EU:457(H2),PR } \\
\text { O:460,VAL:424 } \\
\text {,HIS:458,ILE:4 } \\
16\end{array}$ & $1.000 \AA$ & $\begin{array}{l}56 x \\
64 y \\
60 z\end{array}$ & $\begin{array}{l}34.274 \\
64.058 \\
102.983\end{array}$ \\
\hline $\begin{array}{c}\text { Protein deglycase DJ-1 } \\
\text { (3EZG) }\end{array}$ & -5.22 & $\begin{array}{c}01(\mathrm{H} 1: \text { Distance }= \\
2.88 \AA)\end{array}$ & $\begin{array}{l}\text { CYS53(H1), } \\
\text { VAL50 }\end{array}$ & $1.000 \AA$ & $\begin{array}{l}40 \mathrm{x} \\
40 \mathrm{y} \\
40 \mathrm{z}\end{array}$ & $\begin{array}{c}24.085 \\
-26.704, \\
-12.943 \\
\end{array}$ \\
\hline $\begin{array}{l}\text { Retinoblastoma protein } \\
\qquad(1 \mathrm{~N} 4 \mathrm{M})\end{array}$ & -5.50 & $\begin{array}{c}01 \\
(\mathrm{H} 1: \text { Distance }= \\
1.95 \AA)\end{array}$ & $\begin{array}{l}\text { LYS652(H1), } \\
\text { HIS784 }\end{array}$ & $1.000 \AA$ & $\begin{array}{l}50 x \\
50 y \\
40 z\end{array}$ & $\begin{array}{l}0.441 \\
0.195 \\
-1.114\end{array}$ \\
\hline $\begin{array}{c}\text { Cyclin-dependent } \\
\text { kinase-4 } \\
\text { (3G33) }\end{array}$ & -6.25 & $\begin{array}{c}02 \\
(\mathrm{H} 1: \text { Distance }= \\
3.13 \AA \text { A, } \\
\text { H2:Distance= } \\
\text { 1.98 ̊) }\end{array}$ & $\begin{array}{l}\text { ALA175(H1), } \\
\text { GLN173(H2), } \\
\text { ALA21, } \\
\text { VAL181 }\end{array}$ & $1.000 \AA$ & $\begin{array}{l}50 \mathrm{x} \\
50 \mathrm{y} \\
50 \mathrm{z}\end{array}$ & $\begin{array}{l}-36.014 \\
-11.986 \\
-57.263\end{array}$ \\
\hline $\begin{array}{c}\text { High-mobility group } \\
\text { AT-hook } 2 \\
\text { (3UXW) }\end{array}$ & -6.61 & 00 & $\begin{array}{l}\text { DC11 } \\
\text { DG2 }\end{array}$ & $0.542 \AA$ & $\begin{array}{l}40 \mathrm{x} \\
80 \mathrm{y} \\
40 \mathrm{z}\end{array}$ & $\begin{array}{c}24.584 \\
25.281 \\
5.658\end{array}$ \\
\hline
\end{tabular}

In the interaction of CPX with Catenin beta-1 (1JPW), it was discovered that this ligand located itself in the catalytic site of proteins, which is formed by one hydrogen bonded amino acid residue with a binding energy of $-4.90 \mathrm{Kcal} / \mathrm{mol}$. One hydrogen bond, Gln 322 of catenin, was involved in the interaction of Catenin beta-1 (1JPW) and CPX at distances of $2.07 \AA$ (Figure 1). This inhibitor had no pi-pi interactions, but it did have hydrophobic interactions with catenin residues.

The five amino residues Ile281, Ile273, and Leu277 form the interacting elements of the catalytic site of the proteins in the interactions of CPX with the protein Cdc25A (1C25) with $-4.96 \mathrm{Kcal} / \mathrm{mol}$ binding energy. The interaction reveals two hydrogen bonds with residues, namely Leu42 and Val244, at distances of $2.76 \AA$ and $3.26 \AA$, respectively (Figure 2). 


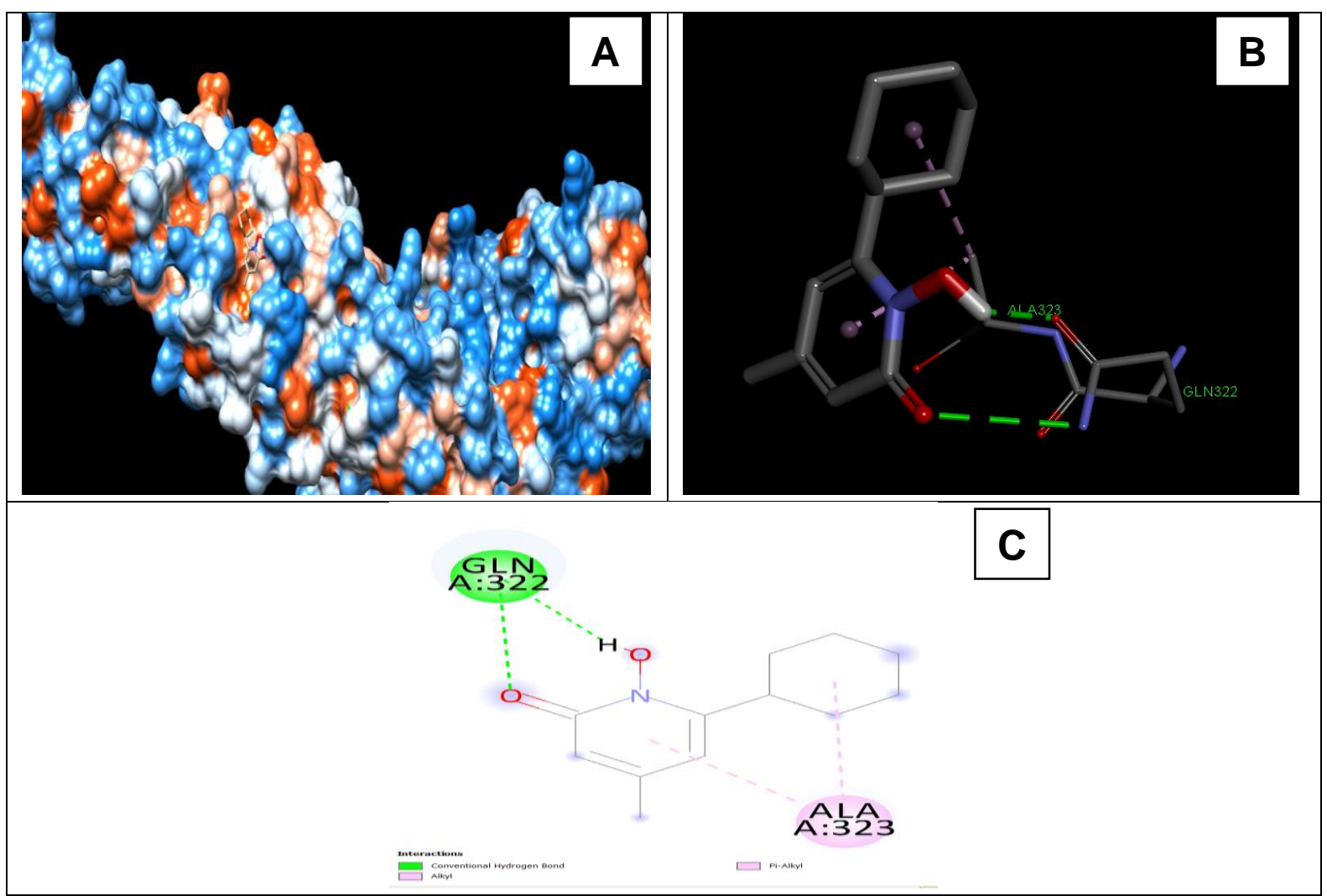

Figure 1. Ciclopirox docked in the Catenin beta-1 (PDB ID: IJPW) protein pocket with (A) best binding mode (ligand as sticks), (B) amino acid residues involved in the interaction, and (C) Ciclopirox binding interaction with an amino acid with a hydrogen bond (green dashed line).

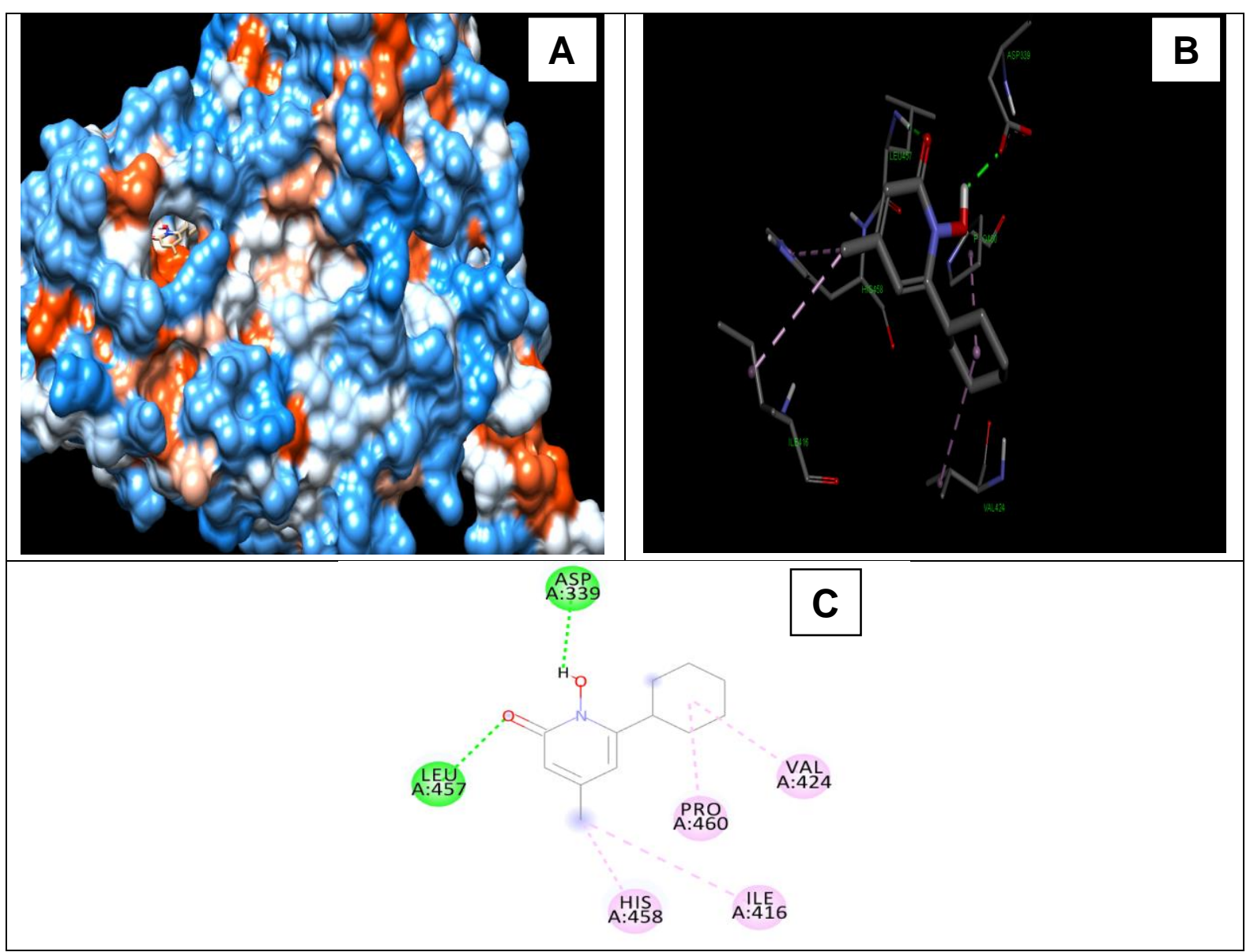

Figure 2. Ciclopirox docked in the Cell division cycle 25 A (PDB ID: 1C25) with (A) best binding mode in the protein pocket (ligand as sticks), (B) amino acid residues involved in the interaction, and (C) binding interaction of Ciclopirox with an amino acid with a hydrogen bond (green dashed line). 


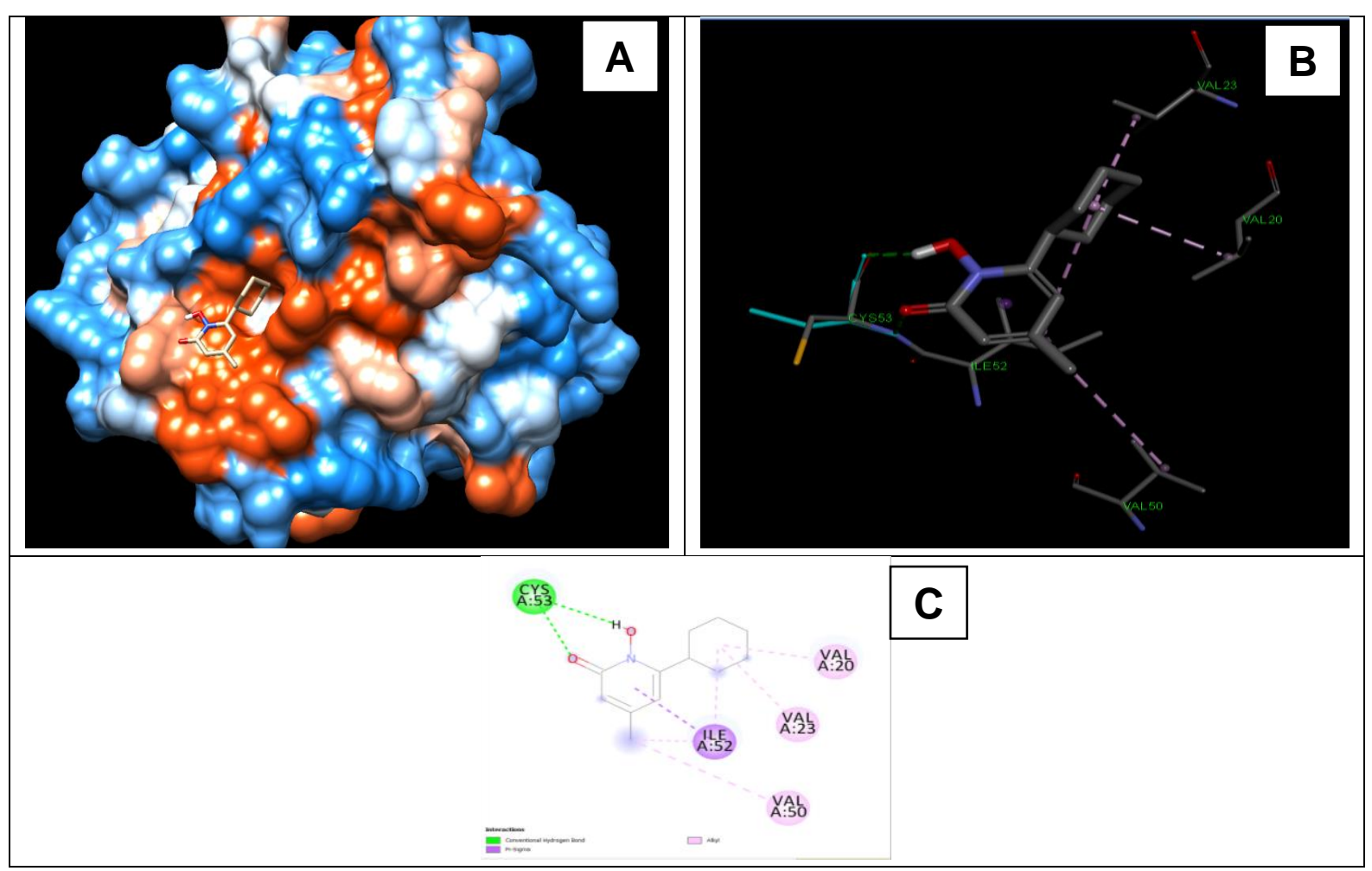

Figure 3. Ciclopirox docked in the Protein deglycase DJ-1 (PDB ID: 3EZG) with (A) the strongest binding mode in the protein pocket (ligand as sticks), (B) amino acid residues involved in the interaction, and (C) Ciclopirox-amino acid-binding interaction with a hydrogen bond (green dashed line).
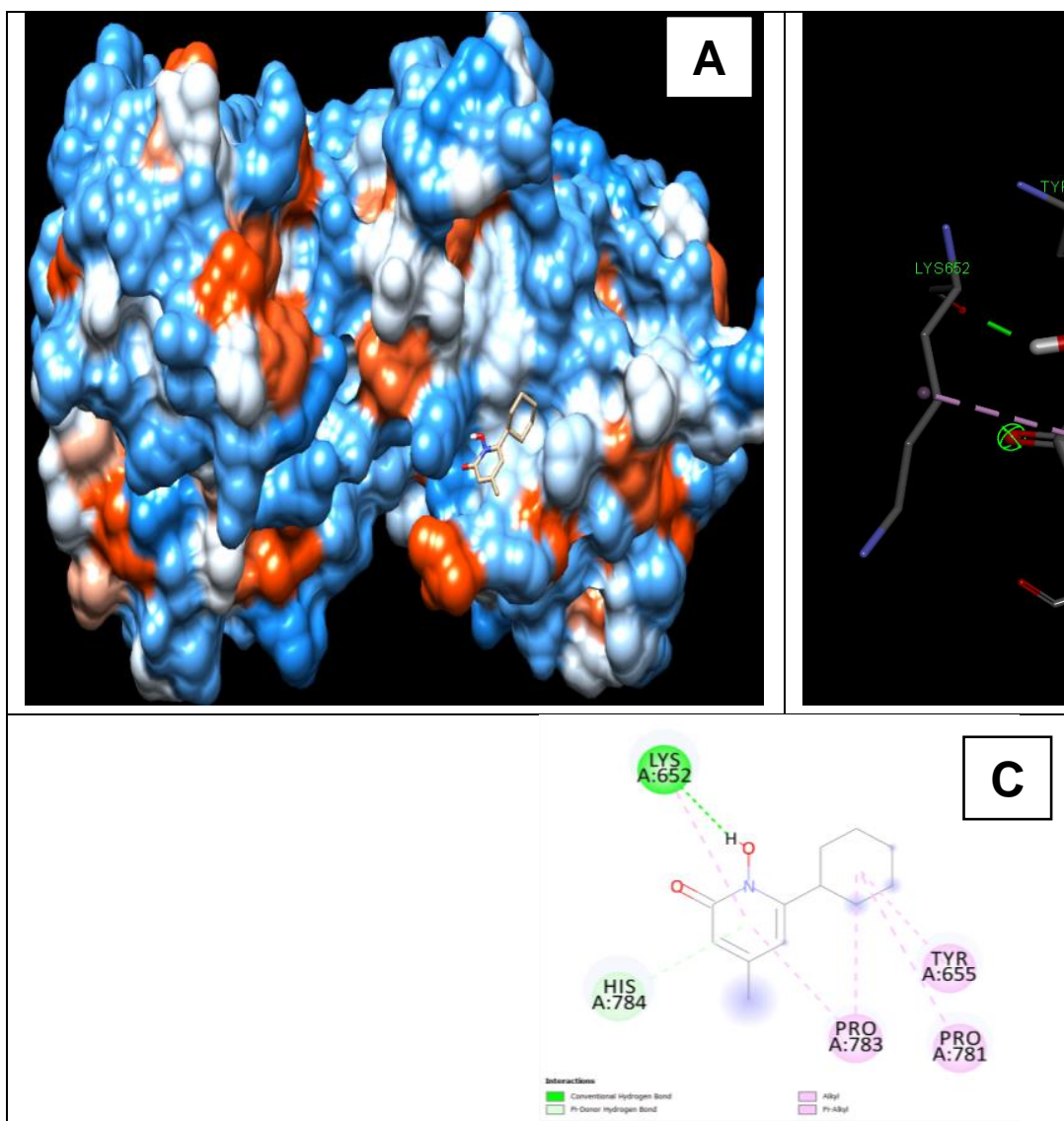

Figure 4. Ciclopirox docked in the Retinoblastoma protein (PDB ID: 1N4M) with (A) the strongest binding mode in the protein pocket (ligand as sticks), (B) amino acid residues involved in the interaction, and $(\mathbf{C})$ Ciclopirox-amino acid-binding interaction with a hydrogen bond (green dashed line). 
In the interactions of CPX with protein deglycase DJ-1 (3EZG), it was observed that the catalytic site of protein interacting with ligands is formed by amino acid Val50 and one hydrogen bonded amino residue Cys53 with binding energy $-5.22 \mathrm{Kcal} / \mathrm{mol}$ along with a distance of $2.88 \AA$ (Figure 3).

During the interactions of CPX with Retinoblastoma protein (1N4M), it was found that the ligand is bound into the catalytic site of proteins with two amino acids; His784, and one hydrogen bond at a distance of $1.95 \AA$ amino acid Lys652 with a binding energy of -5.50 Kcal/mol (Figure 4).

CPX interacting with Cyclin-dependent kinase 4 (3G33) having catalytic site formed by the four amino acids like Ala21 and Val181. The two hydrogen bond amino residues like alanine (ALA175) and glutamine (GLN173) at a distance of $3.13 \AA$ with binding energy -6.25 $\mathrm{Kcal} / \mathrm{mol}$ (Figure 5).

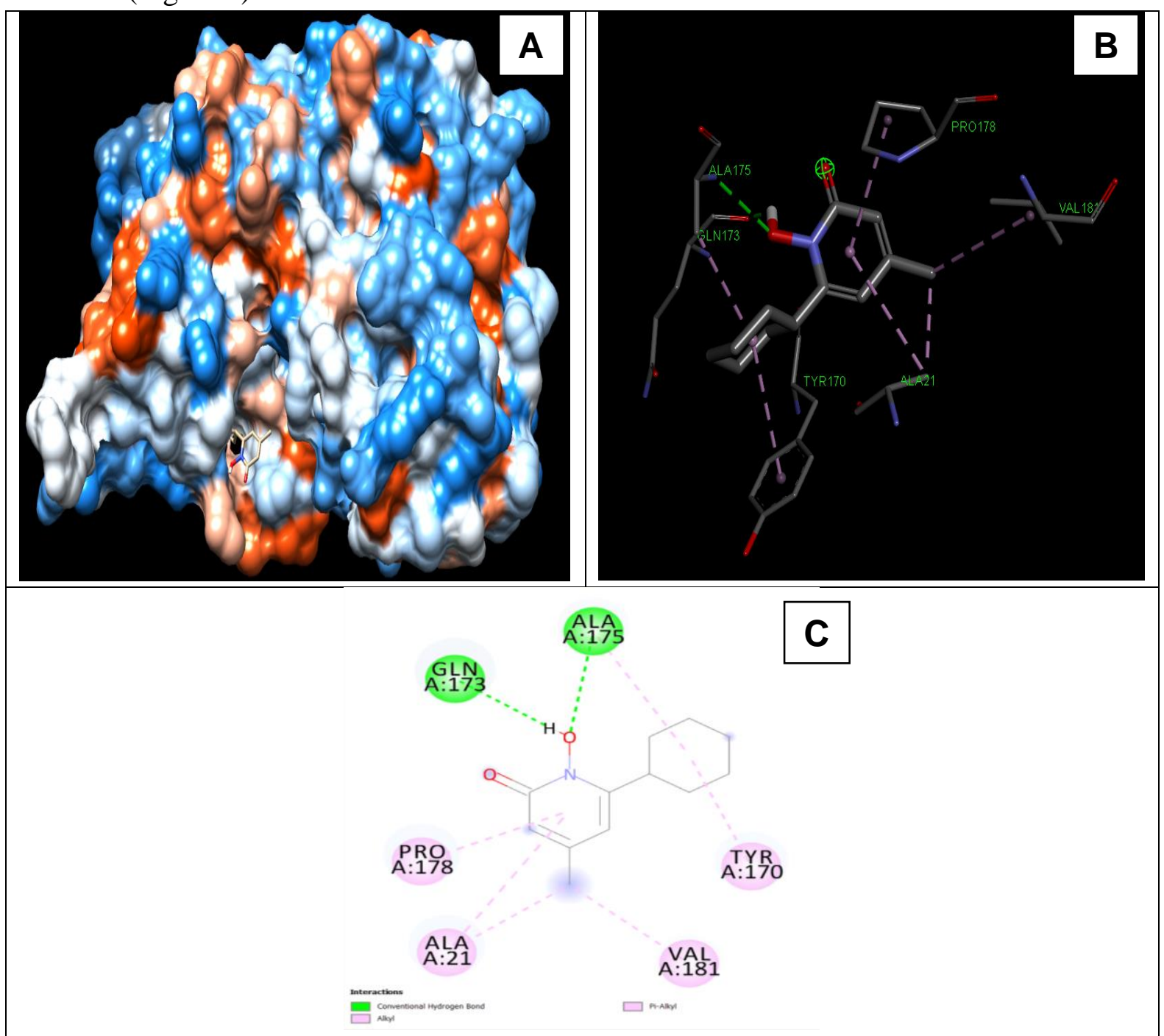

Figure 5. Ciclopirox docked in the Cyclin-dependent kinase 4 (PDB ID: 3G33) with (A) best binding mode in the protein pocket (ligand as sticks), (B) amino acid residues involved in the interaction, and (C) binding interaction of Ciclopirox with an amino acid with a hydrogen bond (green dashed line).

The catalytic site formed by two amino residues like DC11 and DG2 with binding energy $-6.61 \mathrm{Kcal} / \mathrm{mol}$ catalyzes CPX's interactions with High-mobility group AT-hook 2 (3UXW) (Figure 6).

To compare our findings to those of OPL (Table 2), a drug that was approved by the US Food and Drug Administration in 2002, was employed as a reference. 


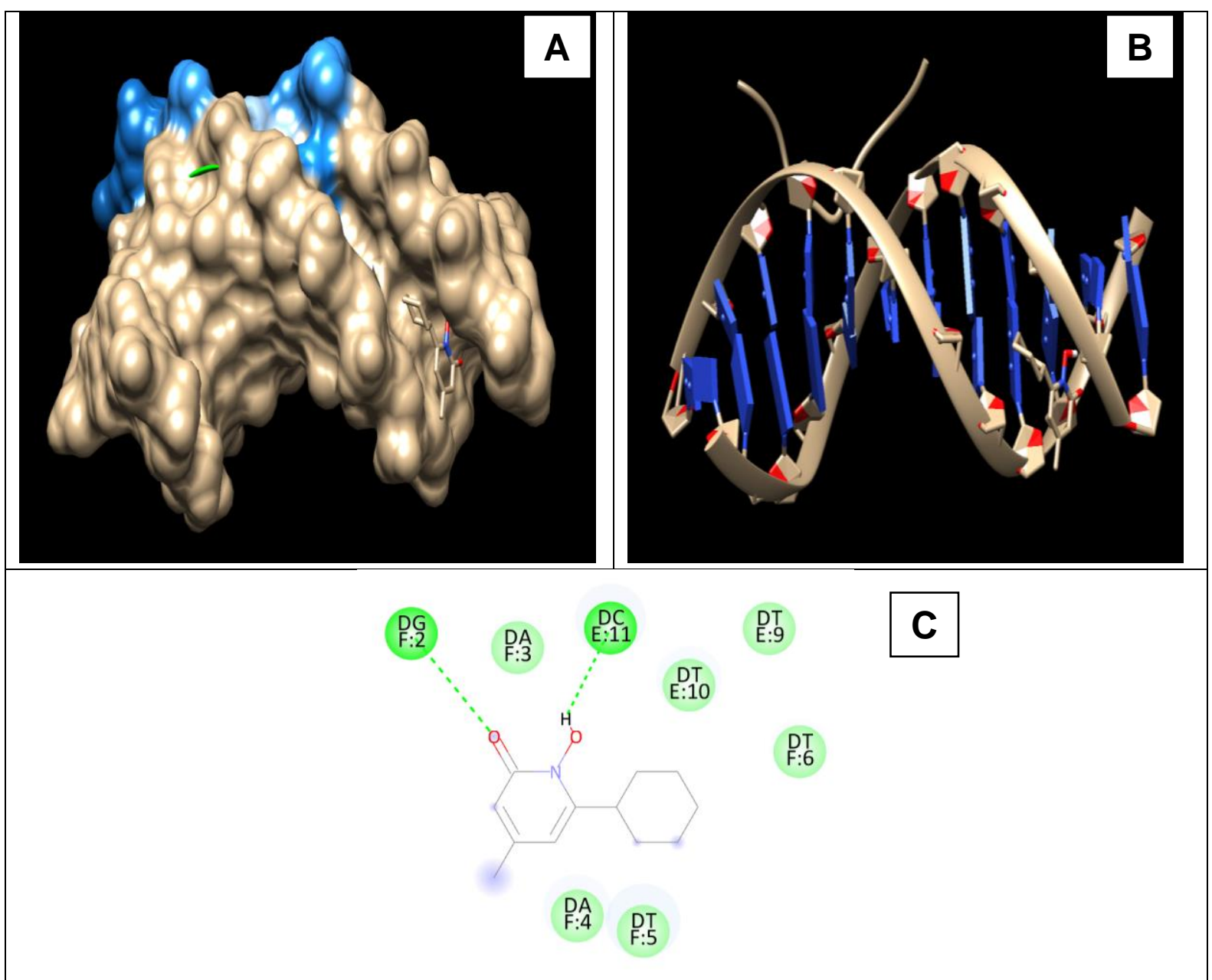

Figure 6. Ciclopirox docked in the High-mobility group AT-hook 2 (PDB ID: 3UXW) with (A) best binding mode in the protein pocket (ligand as sticks); (B) amino acid residues involved in the interaction; (C) binding interaction of Ciclopirox with an amino acid with a hydrogen bond (green dashed line).

Table 2. Interaction of oxaliplatin against various anticancer targets of CRC.

\begin{tabular}{|c|c|c|c|c|c|c|}
\hline $\begin{array}{l}\text { Protein } \\
\text { Name }\end{array}$ & $\begin{array}{l}\text { Binding } \\
\text { Energy* }\end{array}$ & No. of $\mathrm{H}$ Bonds & $\begin{array}{l}\text { Interacting } \\
\text { residue }\end{array}$ & $\begin{array}{l}\text { GridPoint } \\
\text { Spacing }\end{array}$ & $\begin{array}{l}\text { Grid } \\
\text { points }\end{array}$ & $\begin{array}{c}\text { Coordinates } \\
\text { of Central } \\
\text { Grid Point } \\
\text { of Map }\end{array}$ \\
\hline $\begin{array}{l}\text { Catenin beta-1 } \\
\text { (1JPW) }\end{array}$ & -6.02 & $\begin{array}{c}05 \\
(\mathrm{H} 1: \text { Distance }=2.4 \AA, \\
\mathrm{H} 2: \text { Distance }=3.30 \AA, \\
\mathrm{H} 3: \text { Distance }=1.86 \AA, \\
\mathrm{H} 4: \text { Distance }=2.00 \AA, \\
\mathrm{H} 5: \text { Distance }=1.83 \AA)\end{array}$ & $\begin{array}{l}\text { TRP:383(H1),C } \\
\text { YS:419(H2),AR } \\
\text { G:386(H3,THR: } \\
\text { 418(H4),ASN:4 } \\
\text { 15(H5),ASP:45 } \\
\text { 9, ARG:457 }\end{array}$ & $\begin{array}{l}1.000 \\
\text { Angstroms }\end{array}$ & $\begin{array}{l}66 \mathrm{x} \\
98 \mathrm{y} \\
110 \mathrm{z}-\end{array}$ & $\begin{array}{c}106.129 \\
-4.253 \\
18.577\end{array}$ \\
\hline $\begin{array}{l}\text { Cell division } \\
\text { cycle } 25 \mathrm{~A} \\
(1 \mathrm{C} 25)\end{array}$ & -6.63 & 00 & $\begin{array}{l}\text { ASP:492, } \\
\text { GLU:491 }\end{array}$ & $\begin{array}{c}1.000 \\
\text { Angstroms }\end{array}$ & $\begin{array}{l}50 \mathrm{x} \\
60 \mathrm{y} \\
58 \mathrm{z}-\end{array}$ & $\begin{array}{c}6.274,32.058 \\
72.983\end{array}$ \\
\hline $\begin{array}{c}\text { Protein } \\
\text { deglycase DJ- } \\
1 \\
(3 \mathrm{EZG})\end{array}$ & -4.85 & $\begin{array}{c}01 \\
(\mathrm{H} 1: \text { Distance }=2.53 \AA)\end{array}$ & $\begin{array}{c}\text { LYS: } 122, \\
\text { GLY:120(H1), } \\
\text { ASP:149 }\end{array}$ & $\begin{array}{c}1.000 \\
\text { Angstroms }\end{array}$ & $\begin{array}{l}48 \mathrm{x} \\
48 \mathrm{y} \\
40 \mathrm{z}-\end{array}$ & $\begin{array}{l}24.057 \\
-26.699 \\
-12.908\end{array}$ \\
\hline $\begin{array}{l}\text { Retinoblastom } \\
\text { a protein } \\
(1 \mathrm{~N} 4 \mathrm{M})\end{array}$ & -6.42 & 00 & $\begin{array}{l}\text { GLU:667, } \\
\text { GLU:667, } \\
\text { PRO:674 }\end{array}$ & $\begin{array}{c}1.000 \\
\text { Angstroms }\end{array}$ & $\begin{array}{l}70 \mathrm{x} \\
68 \mathrm{y} \\
58 \mathrm{z}-\end{array}$ & $\begin{array}{l}0.441,0.195 \\
-1.114\end{array}$ \\
\hline $\begin{array}{c}\text { Cyclin- } \\
\text { dependent } \\
\text { kinase-4 } \\
(3 \mathrm{G} 33)\end{array}$ & -5.79 & $\begin{array}{c}02 \\
(\mathrm{H} 1: \text { Distance }=2.34 \AA \\
\mathrm{H} 2: \text { Distance }=2.15 \AA)\end{array}$ & $\begin{array}{l}\text { ARG:260(H1), } \\
\text { LEU(H2), } \\
\text { VAL:262, } \\
\text { VAL:265 }\end{array}$ & $\begin{array}{c}1.000 \\
\text { Angstroms }\end{array}$ & $\begin{array}{l}58 \mathrm{x} \\
60 \mathrm{y} \\
58 \mathrm{z}-\end{array}$ & $\begin{array}{l}-36.014 \\
-11.986 \\
-57.263\end{array}$ \\
\hline
\end{tabular}




\begin{tabular}{|c|c|c|c|c|c|c|}
\hline $\begin{array}{l}\text { Protein } \\
\text { Name }\end{array}$ & $\begin{array}{l}\text { Binding } \\
\text { Energy* }\end{array}$ & No. of $\mathrm{H}$ Bonds & $\begin{array}{l}\text { Interacting } \\
\text { residue }\end{array}$ & $\begin{array}{l}\text { GridPoint } \\
\text { Spacing }\end{array}$ & $\begin{array}{l}\text { Grid } \\
\text { points }\end{array}$ & $\begin{array}{l}\text { Coordinates } \\
\text { of Central } \\
\text { Grid Point } \\
\text { of Map }\end{array}$ \\
\hline $\begin{array}{l}\text { High-mobility } \\
\text { group AT- } \\
\text { hook } 2 \\
(3 \mathrm{UXW})\end{array}$ & -7.71 & $\begin{array}{c}04 \\
(\mathrm{H} 1: \text { Distance }=1.83 \AA, \\
\mathrm{H} 2: \text { Distance }=1.94 \AA, \\
\text { H3: Distance }=2.93 \AA, \\
\text { H4:Distance }=2.43 \AA, \text { }\end{array}$ & $\begin{array}{c}\text { ARG:38, } \\
\text { DA:8(H1), } \\
\text { DT:6(H2), } \\
\text { DT:5(H3), } \\
\text { DT:9(H4), } \\
\text { DT:10, DC:11, } \\
\text { DA:7 }\end{array}$ & $\begin{array}{c}1.000 \\
\text { Angstroms }\end{array}$ & $\begin{array}{l}40 \mathrm{x}, \\
46 \mathrm{y} \\
40 \mathrm{z}\end{array}$ & $\begin{array}{c}24.584,25.281 \\
5.658\end{array}$ \\
\hline
\end{tabular}

In the interaction of OPL with Catenin beta-1 (1JPW), it was discovered that this ligand located itself in the catalytic site of proteins, which is formed by seven hydrogen-bonded amino residues (Trp383, Cys419, Arg386, Thr418, Asn415, Asp459, and Arg457) with a binding energy of $-6.02 \mathrm{Kcal} / \mathrm{mol}$ at distances of $2.4 \AA$, $3.30 \AA$, $1.86 \AA, 2.00 \AA, 1.83 \AA$ (Figure 7), respectively.

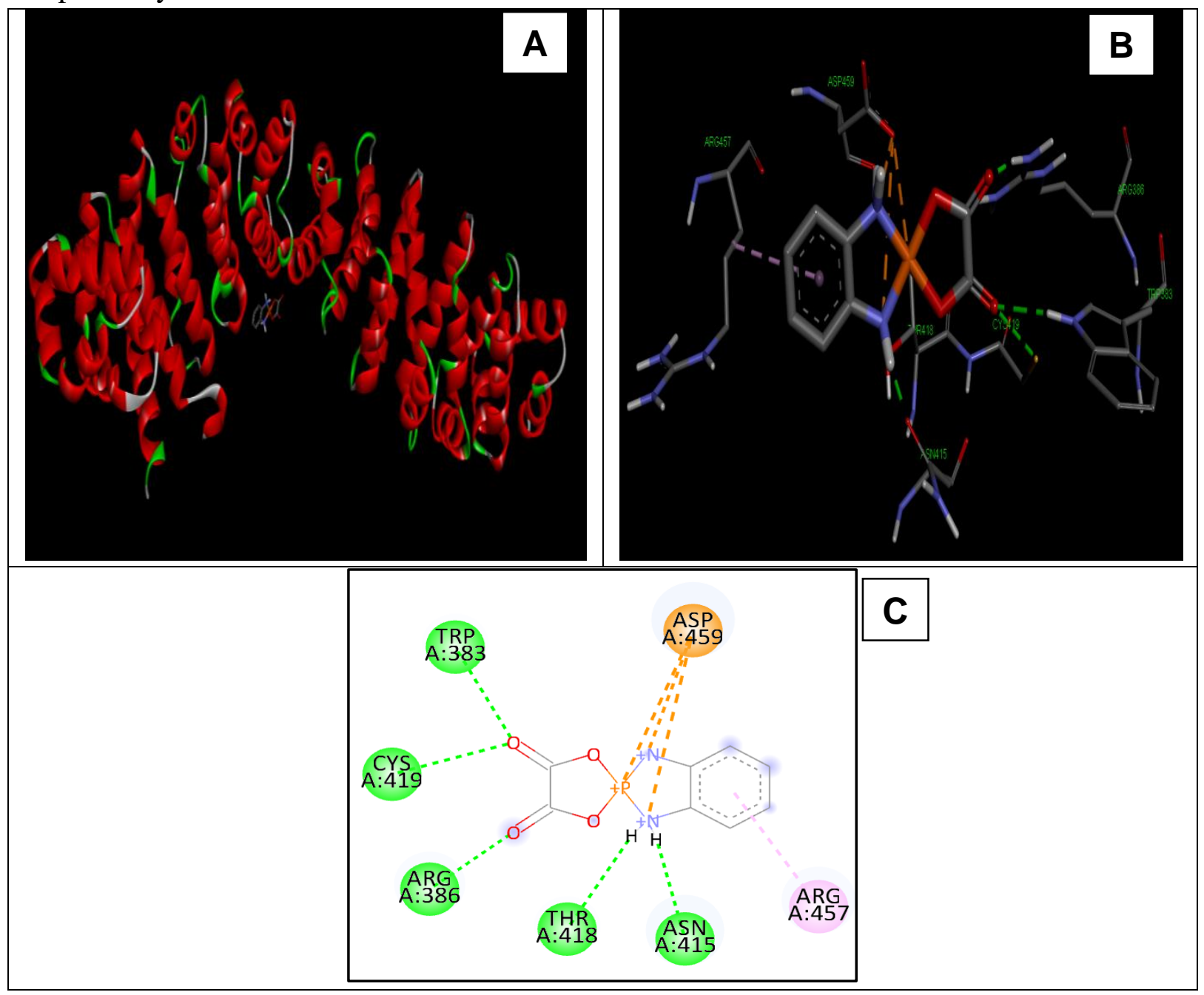

Figure 7. Oxaliplatin docked in the Catenin beta-1 (PDB ID: IJPW) protein pocket with (A) best binding mode (ligand as sticks), (B) amino acid residues involved in the interaction, and (C) oxaliplatin binding interaction with an amino acid with a hydrogen bond (green dashed line). 


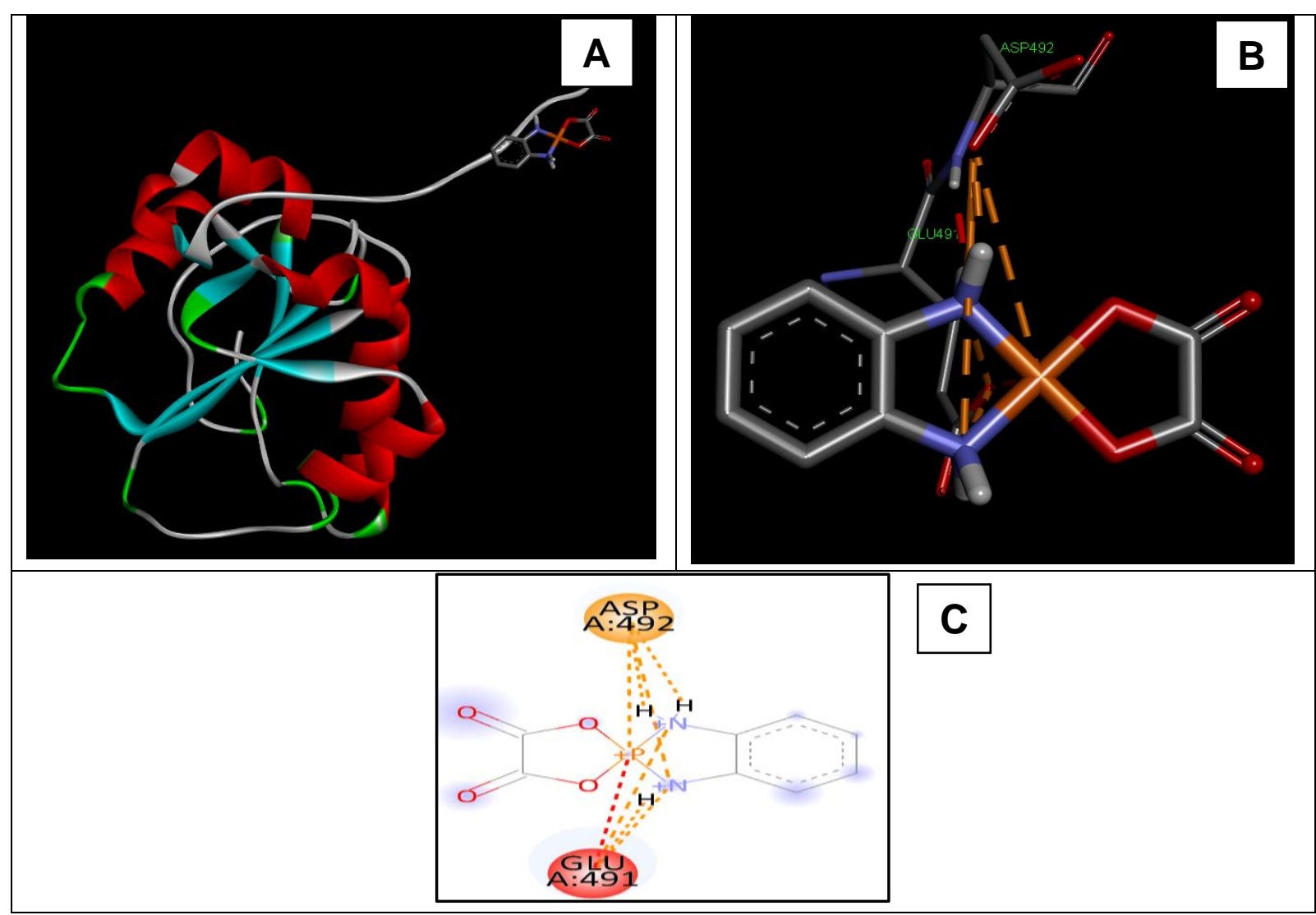

Figure 8. Oxaliplatin docked in the High-mobility group Cell division cycle 25 A (PDB ID: 1C25) with (A) best binding mode in the protein pocket (ligand as sticks), (B) amino acid residues involved in the interaction, and

(C) binding interaction of oxaliplatin with an amino acid with a hydrogen bond (green dashed line).

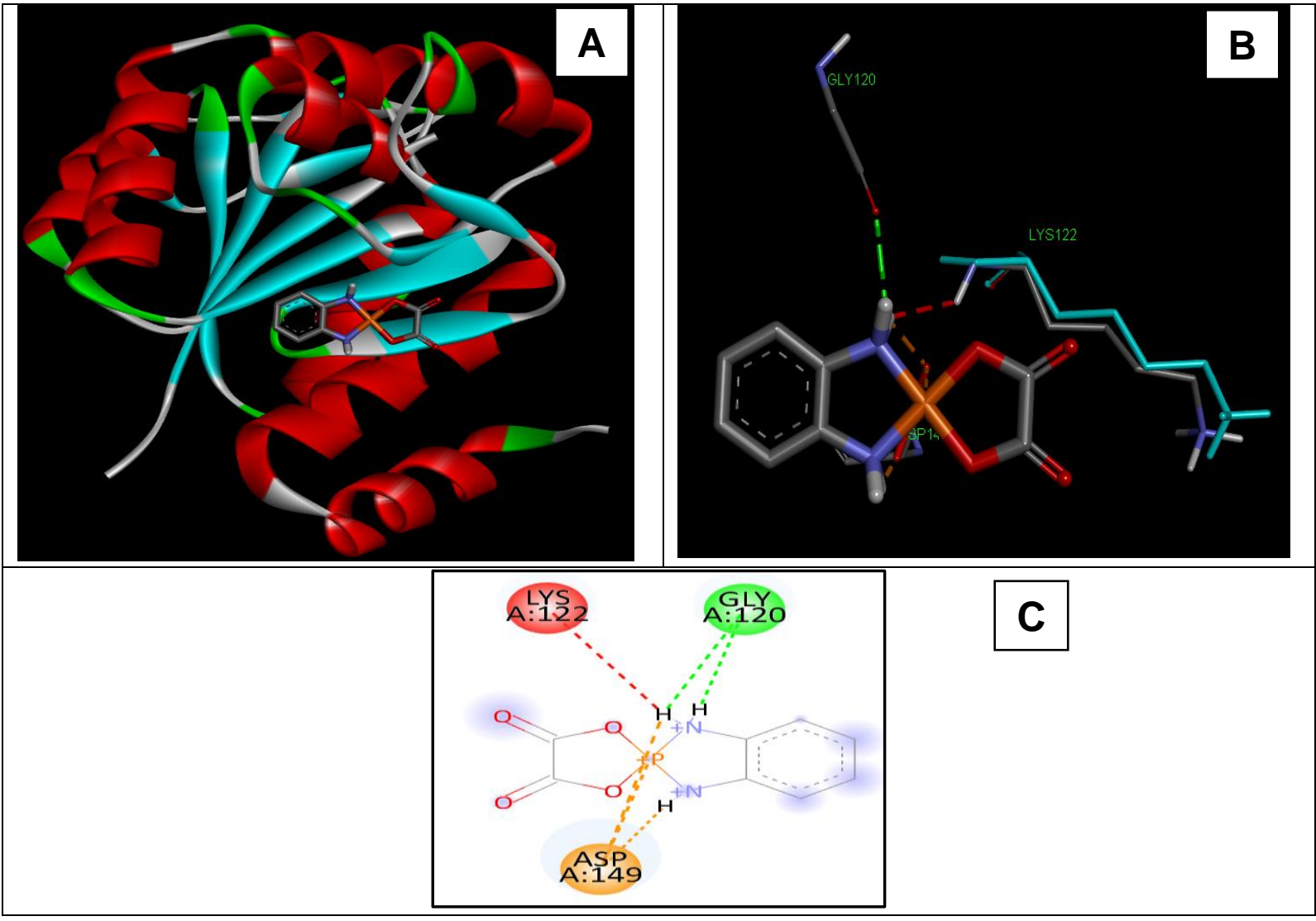

Figure 9. Oxaliplatin docked in the protein deglycase DJ-1 (PDB ID: 3EZG) with (A) the strongest binding mode in the protein pocket (ligand as sticks), (B) amino acid residues involved in the interaction, and (C) oxaliplatin-amino acid-binding interaction with a hydrogen bond (green dashed line). 
OPL binds to the catalytic site of proteins, which is constituted by a hydrogen-bonded amino acid with a binding energy of $-6.63 \mathrm{Kcal} / \mathrm{mol}$, during its interaction with $\mathrm{Cdc} 25 \mathrm{~A}$ (1C25). Asp492 and Glu491 were the key amino acids that are engaged in the interaction of Cdc25A and oxaliplatin. There were no pi-pi interactions with this inhibitor. However, it did exhibit hydrophobic interactions with residues (Figure 8).

In the interactions of OPL with protein deglycase DJ-1 (3EZG), it was observed that the catalytic sites of protein interacting with ligands are formed by amino acid residues; Lys122, Gly120, and Asp149 with binding energy -4.85 Kcal/mol along with a hydrogenbonding distance of $2.53 \AA$ (Figure 9).

During the interactions of OPL with Retinoblastoma protein (1N4M), it was found that the ligand is bound into the catalytic site of proteins with two amino acids; Glu667 and Pro674, with a binding energy of $-6.42 \mathrm{Kcal} / \mathrm{mol}$ (Figure 10).

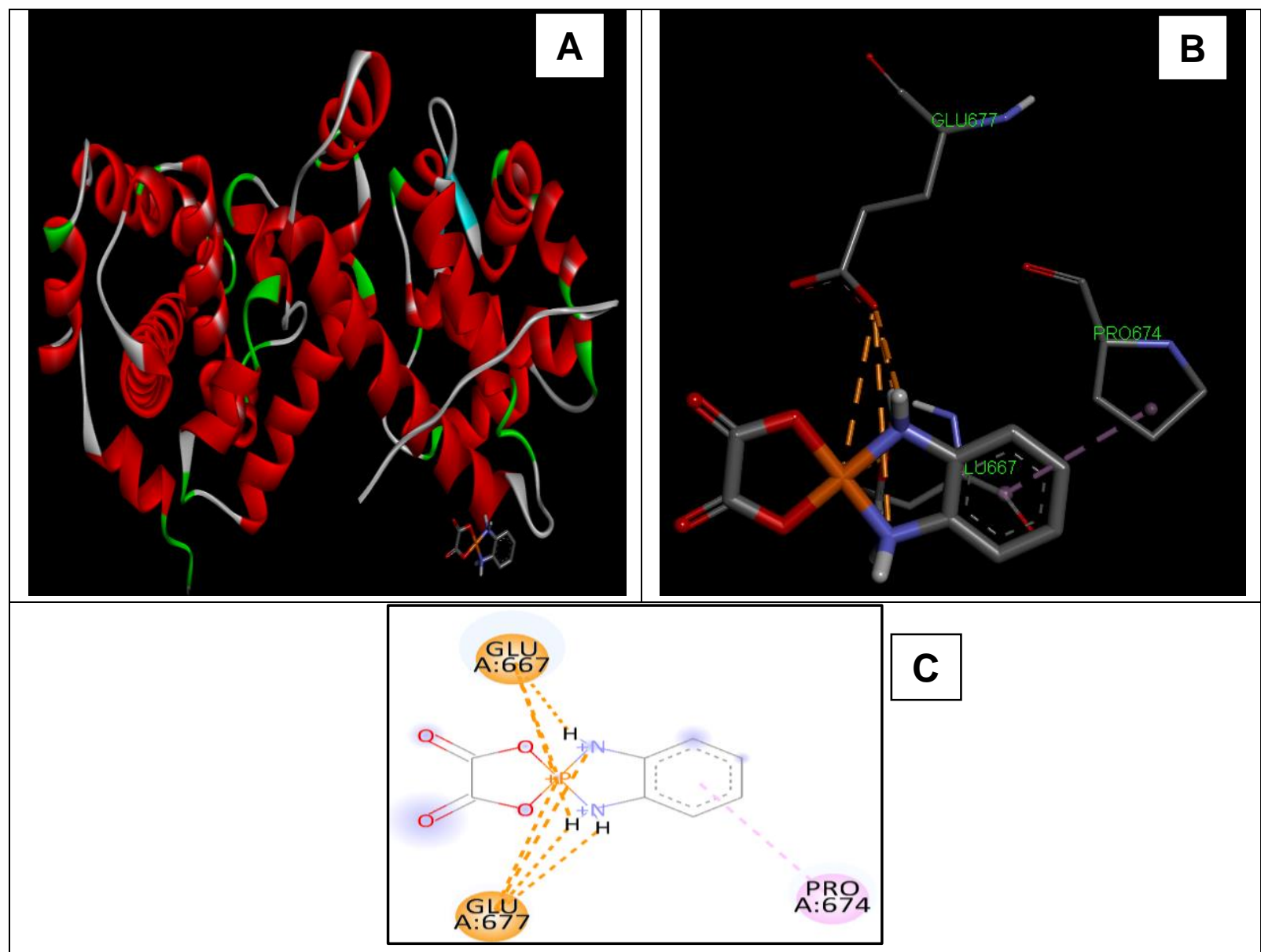

Figure 10. Oxaliplatin docked in the Retinoblastoma protein (PDB ID: 1N4M) with (A) the strongest binding mode in the protein pocket (ligand as sticks), (B) amino acid residues involved in the interaction, and (C)oxaliplatin-amino acid-binding interaction with a hydrogen bond (green dashed line).

OPL is interacting with Cyclin-dependent kinase 4 (3G33), having a catalytic site formed by the three amino acids like Arg260, Ala21, and Val265 at hydrogen bonding distance $2.34 \AA$ and $2.15 \AA$ with binding energy $-5.79 \mathrm{Kcal} / \mathrm{mol}$ (Figure 11).

The catalytic site formed through ARG38as well as three amino residues like DA7, DT10, and DC11 with binding energy $-7.71 \mathrm{Kcal} / \mathrm{mol}$ catalyzes OPL's interactions with Highmobility group AT-hook 2 (3UXW) with hydrogen bond at distances of $1.83 \AA$, $1.94 \AA, 2.93$ $\AA$, and $2.43 \AA$, respectively (Figure 12 ). 


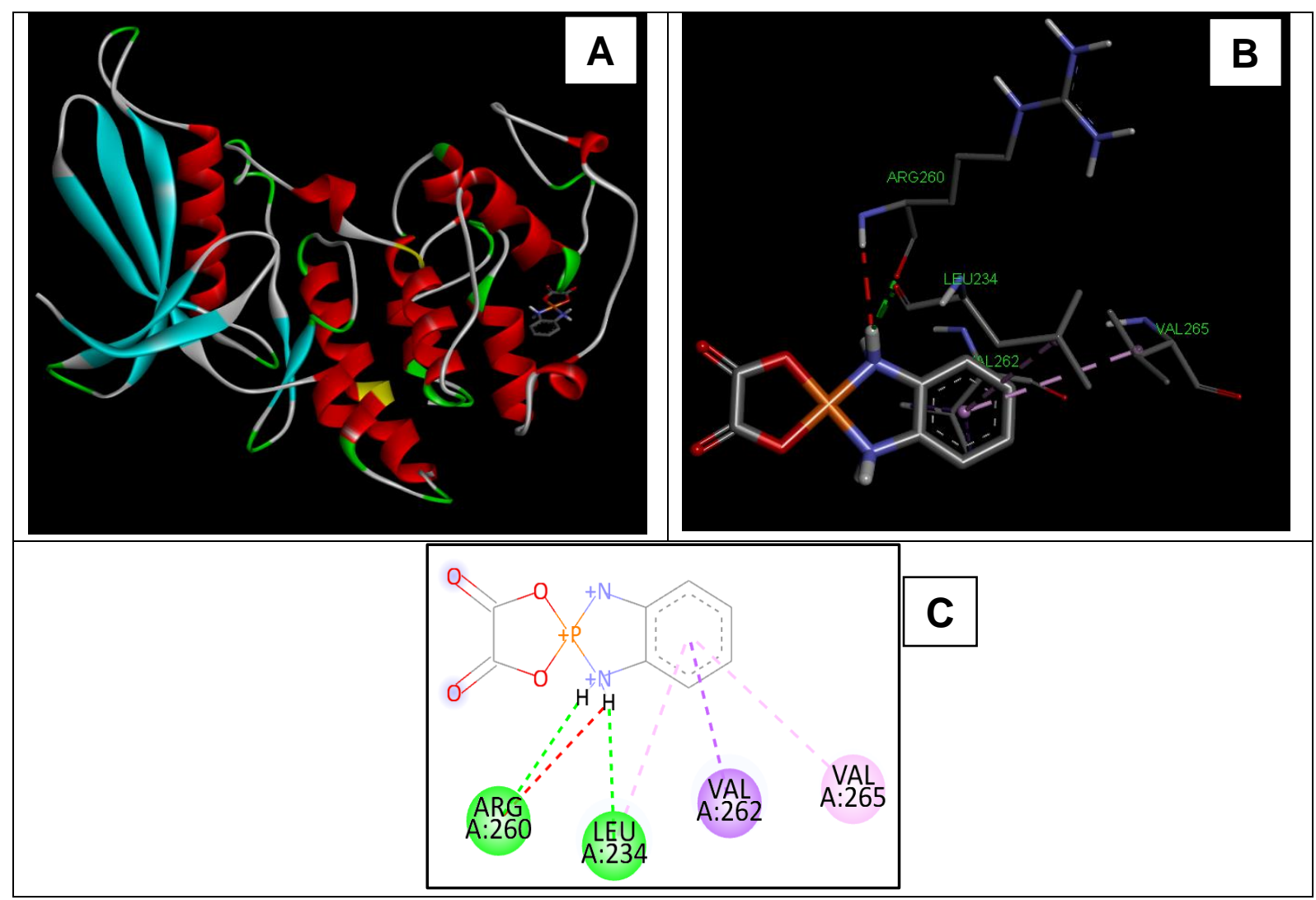

Figure 11.Oxaliplatin docked in the Cyclin-dependent kinase 4 (PDB ID: 3G33) with (A) best binding mode in the protein pocket (ligand as sticks), (B) amino acid residues involved in the interaction, and (C) binding interaction of oxaliplatin with an amino acid with a hydrogen bond (green dashed line).

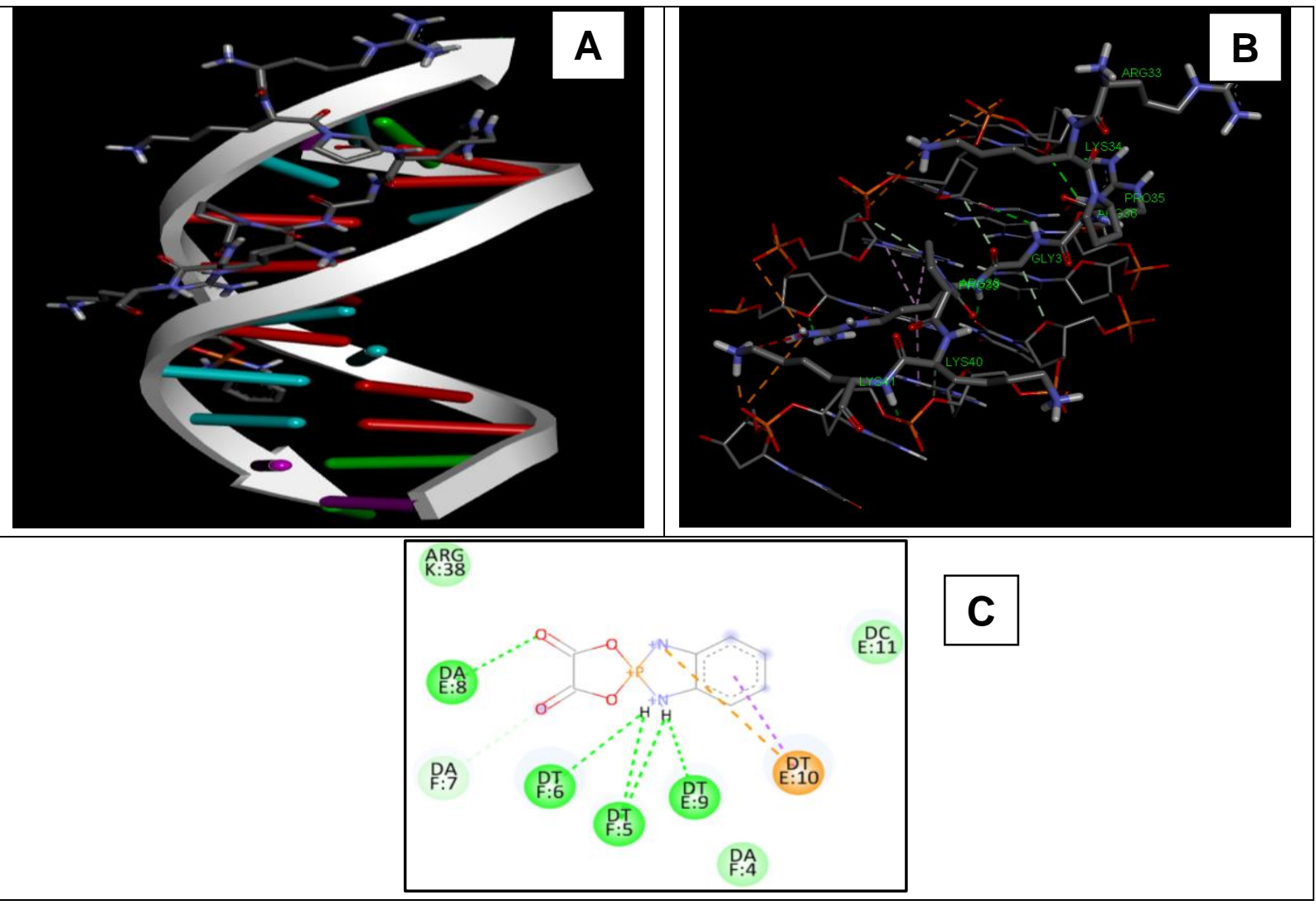

Figure 12. Oxaliplatin docked in the High-mobility group AT-hook 2 (PDB ID: 3UXW) with (A) best binding mode in the protein pocket (ligand as sticks), (B) amino acid residues involved in the interaction, and $(\mathbf{C})$ binding interaction of oxaliplatin with an amino acid with a hydrogen bond (green dashed line). 


\subsection{In silico pharmacokinetics, bioavailability, and drug-likeliness studies.}

Table 3 describes the predictive values for bioavailability, pharmacokinetics, and druglikeness data on CPX. The molecule showed a high absorption rate. Low blood-brain permeability was obtained based on the $\operatorname{LogP}$ value, while a higher negative value indicated lower skin permeation. In the case of metabolism, the molecule did not prove to be a pglycoprotein substrate as well as CYP1A2, CYP2C19, CYP2C9, CYP2D6, and CYP3A4 inhibitors. For the prediction of bioavailability and drug-likeness, a high bioavailability score was obtained. High water solubility was obtained for CPX.

Table 3. Pharmacokinetics and physicochemical properties of Ciclopirox.

Properties

Data

\begin{tabular}{|c|c|}
\hline \multicolumn{2}{|c|}{ Physicochemical Properties } \\
\hline Formula & $\mathrm{C}_{12} \mathrm{H}_{17} \mathrm{NO}_{2}$ \\
\hline Molecular weight & $207.27 \mathrm{~g} / \mathrm{mol}$ \\
\hline Number of heavy atoms & 15 \\
\hline Number of aromatic heavy atoms & 6 \\
\hline Fraction Csp3 & 0.58 \\
\hline Number of rotatable bonds & 1 \\
\hline Number of H-bond acceptors & 2 \\
\hline Number of H-bond donors & 1 \\
\hline Molar Refractivity & 60.10 \\
\hline TPSA & $42.23 \mathrm{~A}^{2}$ \\
\hline \multicolumn{2}{|c|}{ Lipophilicity } \\
\hline Log Po/w (iLOGP) & 2.28 \\
\hline Log Po/w (XLOGP3) & 1.99 \\
\hline Log Po/w (WLOGP) & 2.44 \\
\hline Log Po/w (MLOGP) & 2.67 \\
\hline Log Po/w (SILICOS-IT) & 2.16 \\
\hline Consensus Log Po/w & 2.31 \\
\hline \multicolumn{2}{|c|}{ Water Solubility } \\
\hline $\log \mathrm{S}(\mathrm{ESOL})$ & -2.61 \\
\hline Solubility & $5.10 \mathrm{e}-01 \mathrm{mg} / \mathrm{ml} ; 2.46 \mathrm{e}-03 \mathrm{~mol} / \mathrm{l}$ \\
\hline Class & $\begin{array}{l}\text { Soluble } \\
\end{array}$ \\
\hline Log S (Ali) & -2.50 \\
\hline Solubility & $6.51 \mathrm{e}-01 \mathrm{mg} / \mathrm{ml} ; 3.14 \mathrm{e}-03 \mathrm{~mol} / \mathrm{l}$ \\
\hline Class & Soluble \\
\hline Log S (SILICOS-IT) & -2.36 \\
\hline Solubility & $9.01 \mathrm{e}-01 \mathrm{mg} / \mathrm{ml} ; 4.35 \mathrm{e}-03 \mathrm{~mol} / \mathrm{l}$ \\
\hline Class & $\begin{array}{c}\text { Soluble } \\
\end{array}$ \\
\hline \multicolumn{2}{|c|}{ Pharmacokinetics } \\
\hline GI absorption & High \\
\hline BBB permeant & Yes \\
\hline P-gp substrate & No \\
\hline CYP1A2 inhibitor & No \\
\hline CYP2C19 inhibitor & No \\
\hline CYP2C9 inhibitor & No \\
\hline CYP2D6 inhibitor & No \\
\hline CYP3A4 inhibitor & No \\
\hline Log Kp (skin permeation) & $-6.15 \mathrm{~cm} / \mathrm{s}$ \\
\hline \multicolumn{2}{|c|}{ Drug-likeness } \\
\hline Lipinski & Yes; 0 violation \\
\hline Ghose & Yes \\
\hline Veber & Yes \\
\hline Egan & Yes \\
\hline Muegge & Yes \\
\hline Bioavailability Score & 0.55 \\
\hline
\end{tabular}




\begin{tabular}{c|c} 
Properties & Data \\
\hline \multicolumn{1}{c}{ Medicinal Chemistry } \\
\hline PAINS & 0 alert \\
\hline Brenk & 1 alert: N-hydroxyl_pyridine \\
\hline Lead-likeness & No; 1 violation: MW<250 \\
\hline Synthetic accessibility & 2.51
\end{tabular}

The bioavailability radar for oral bioavailability prediction showed desired INSATU $=$ insaturation as per Csp3 as 0.58, FLEX as per the number of rotatable bond 1, INSOLU Logs (ESOL) as -2.61 (soluble), SIZE as molecular weight (gm/mol) of $207.27 \mathrm{~g} / \mathrm{mol}$, POLAR as TPSA $\left(\AA^{2}\right) 42.23$, and LIPO as XLOGP3 value of 1.99 (Figure 13A).

In the instance of the BOILED-Egg model (Figure 13B), it was discovered that CPX can penetrate the blood-brain barrier and has a high gastrointestinal absorption penetration capacity. In a prediction model, the molecule was discovered to be PGP negative as a nonsubstrate. The Brain Or IntestinaL EstimateD permeation technique (BOILED-Egg) has previously been suggested as a reliable predictive model, which aids in the computational prediction of small-molecule lipophilicity and polarity. According to bioavailability radar and BOILED-Egg representation, CPX might be a good medication candidate in the long run. Furthermore, in vitro and in vivo functional and pharmacological assays should be used to confirm these prognostic findings in order to control CRC.

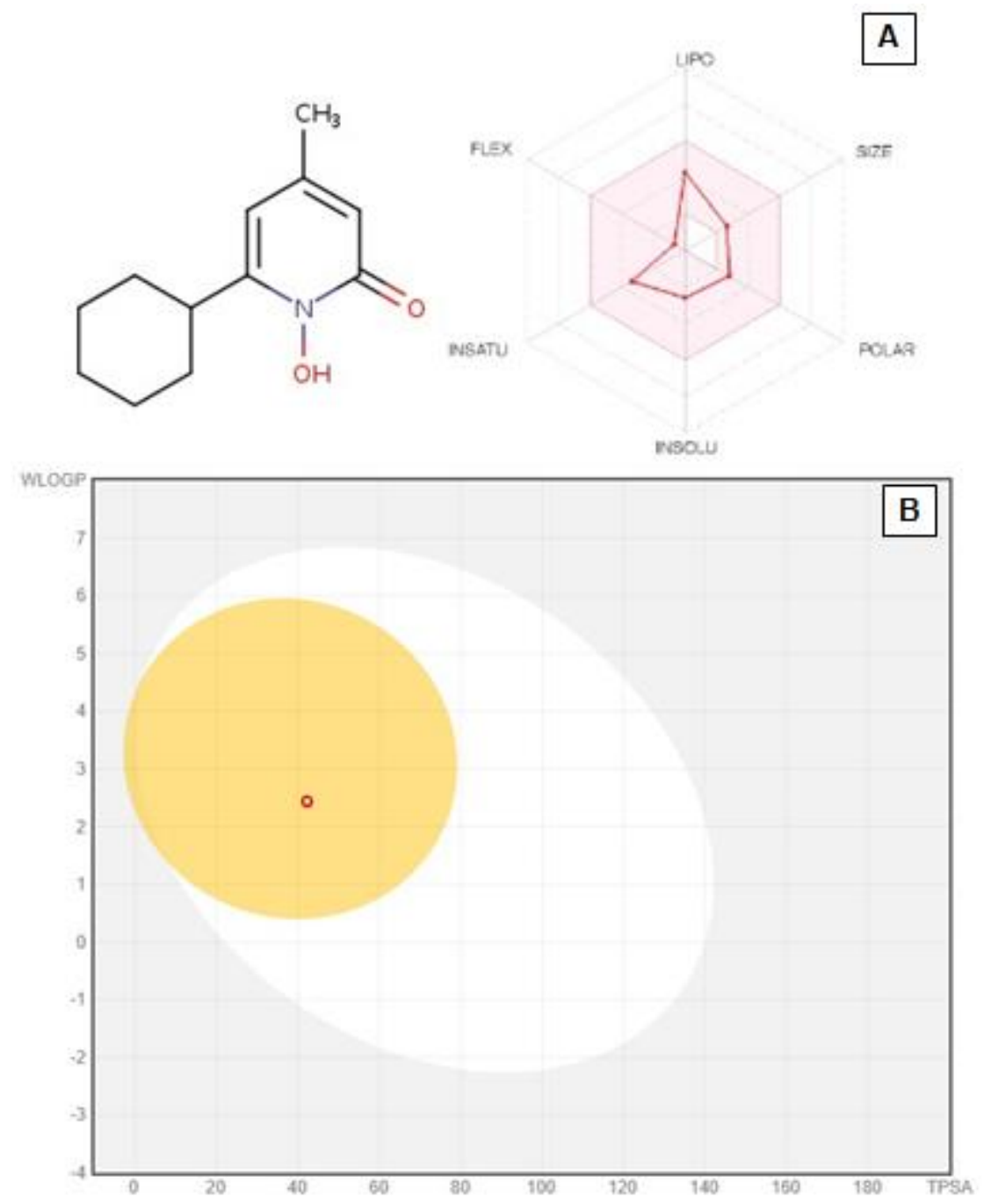

Figure 13. Pharmacokinetic predictions for Ciclopirox: (A) Bioavailability radar plot and (B) BOILED Egg Model. 


\subsection{Drug target identifications.}

As the study is focused on drug repurposing, it remains crucial to determine the plausible therapeutic targets against which CPX can inhibit them with micromolar concentrations, ideally.
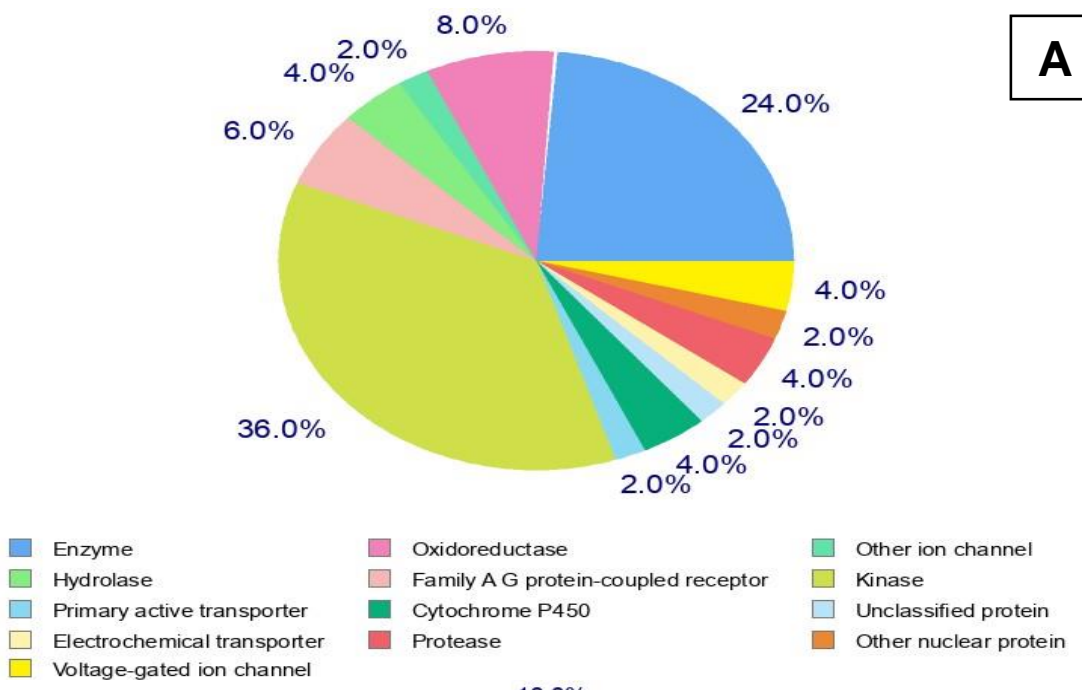

Family A G protein-coupled receptor

- Cytochrome P450

Protease

Other ion channel

$\square$ Kinase

Unclassified protein

$\square$ Voltage-gated ion channel
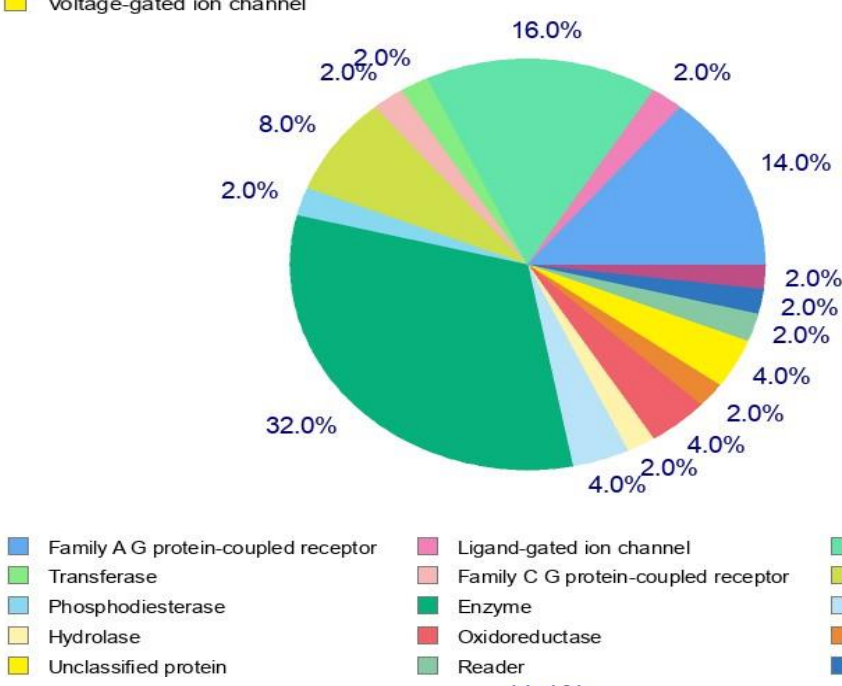

$\square$ Ligand-gated ion channe

$\square$ Family C G protein-coupled receptor

- Enzyme

Oxidoreductase

Other nuclear protein

$\square$ Reader

$11.1 \%$

\section{B}

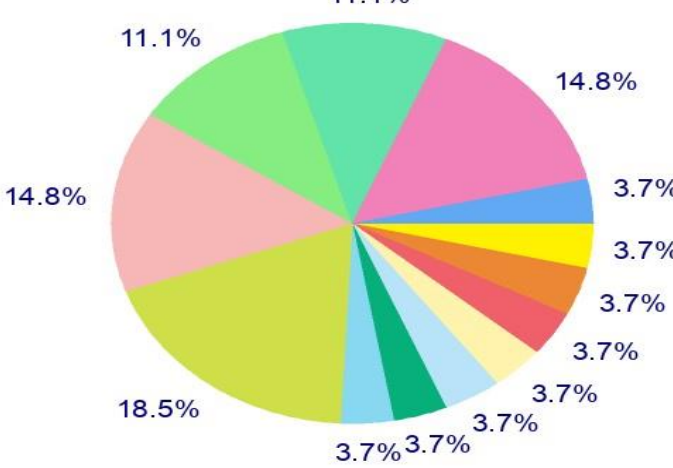

\footnotetext{
$\square$ Lyase

$\square$ Family A G protein-coupled receptor

$\square$ Oxidoreductase

$\square$ Nuclear receptor

Unclassified protein
}

$\square$ Voltage-gated ion channel

Enzyme

Primary active transporter

Hydrolase

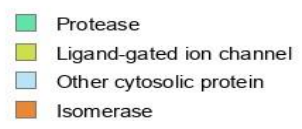

Figure 14. Predicted therapeutic targets of Ciclopirox against (A) human; (B) mouse; (C) rat.

The human (Homo sapiens), rat (Rattus norvegicus), and mouse (Mus musculus) models revealed the inhibitory perspectives of CPX against several targets like hydrolase, enzyme, oxidoreductase, Family A G protein-coupled receptor, transferase, voltage-gated ion 
channel, primary active transporter, ligand-gated ion channel, etc. (Figure 14). The predicted results strongly supported the basis of repurposing this small antifungal molecule for possible applications against $\mathrm{CRC}$ by revealing the possibilities of drug interactions with multiple targets.

\subsection{Bioisosteric studies.}

The bioisosteric study of the core scaffold successfully revealed several imperative data. The strategy of selectively replacing the central scaffold (1,2-dihydropyridine) of CPX with tetrahydropyran, piperidine, piperazine, and morpholine was taken into account for determining the target interaction perspective and structure-activity relationship(s) (Figure 15A). It was observed from the obtained result that the number of interacting targets escalated when the pyrimidine scaffold (adjusted sequentially with 1,2-dihydropyridine) was replaced, in the following order: morpholine (61) > piperidine (54) > tetrahydropyran (36) > piperazine (17). When the pyrimidine scaffold is replaced with tetrahydropyran, the activity remains unchanged when the aromatic ring is replaced at the attachment point, whereas the activity decreases when the aliphatic ring is replaced at the attachment point (Figure 15B). When the pyrimidine scaffold is replaced with piperidine, the activity remains unchanged when the aromatic ring is replaced at the attachment point, whereas the activity increases when the aliphatic ring is replaced at the attachment point (Figure 15C). When the pyrimidine scaffold was replaced with morpholine, the activity remained unchanged when the aromatic ring and aliphatic linker were replaced at attachment points (Figure 15D). Analogous results were observed when the pyrimidine scaffold was replaced with piperazine (Figure 15E). The changes in $\log$ P value (lipophilicity), tPSA, and molecular weight and its influence were found to be negligible.

\section{Discussion}

CRC has become a worldwide crisis. Scientists and medics are looking for viable therapeutic medications, and there is a pressing need to find effective treatments with fewer side effects to combat cancer. Molecular docking is a useful computational approach for finding possible drug candidates and drug discovery [24].

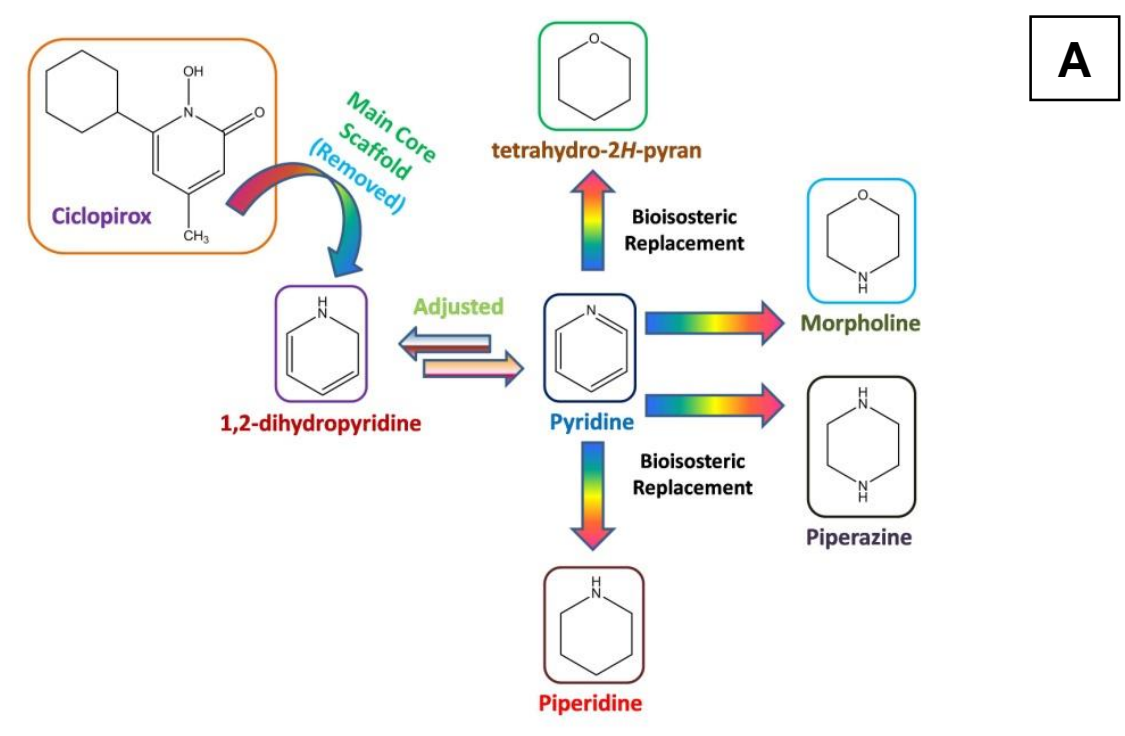



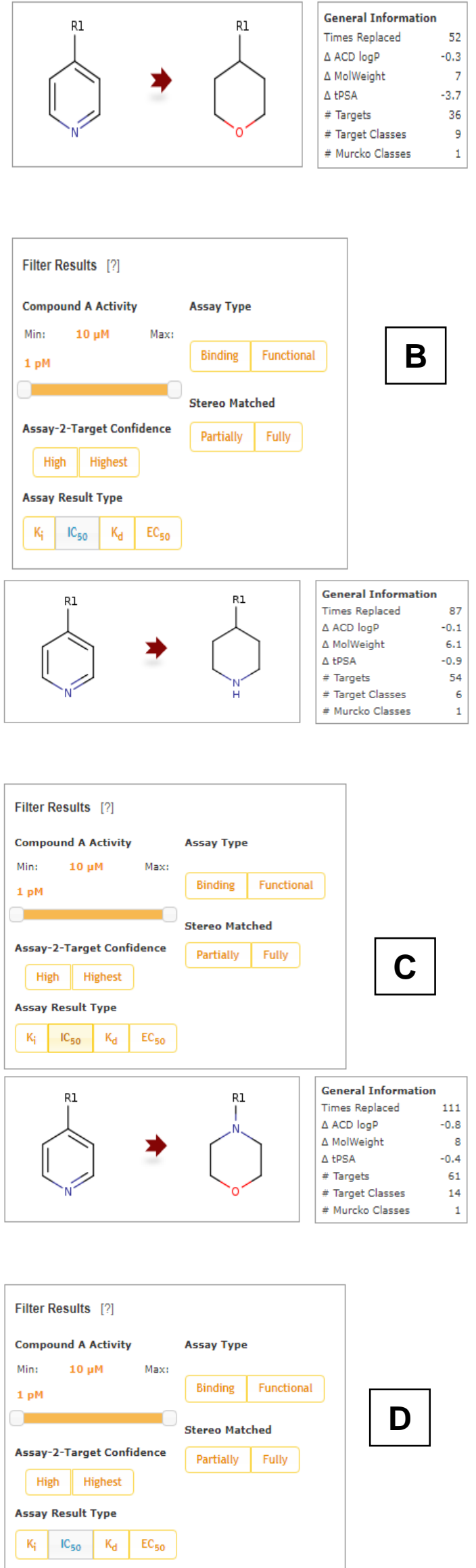

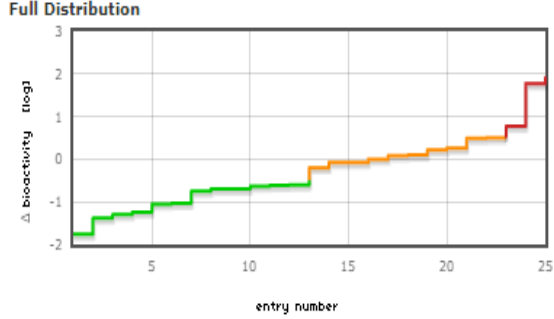

Distribution by Attachment Point Context R1-Aromatic Ring R1- Aliphatic Ring R1- Aliphatic Linker
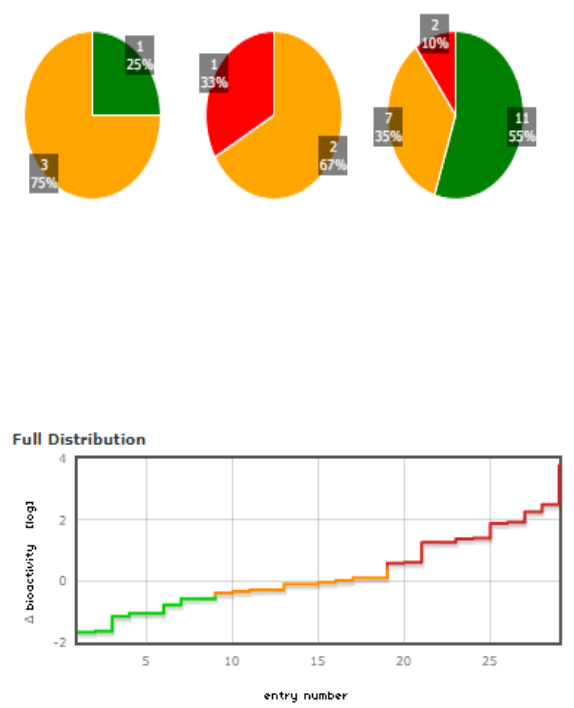

Distribution by Attachment Point Context R1-Aromatic Ring R1-Aliphatic Ring R1-Aliphatic Linker
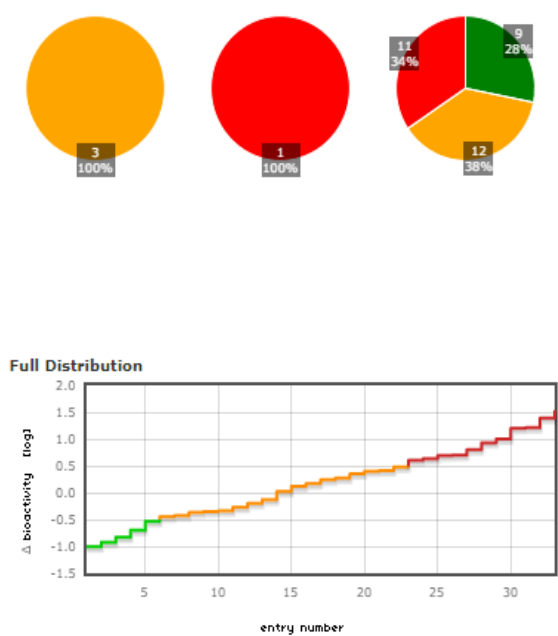

Distribution by Attachment Point Context

R1-Aromatic Ring R1-Aliphatic Ring R1-Aliphatic Linker
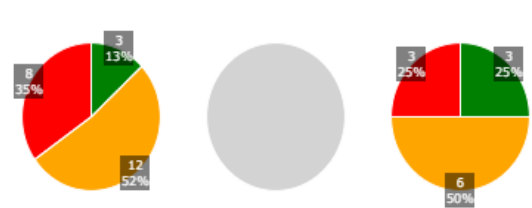

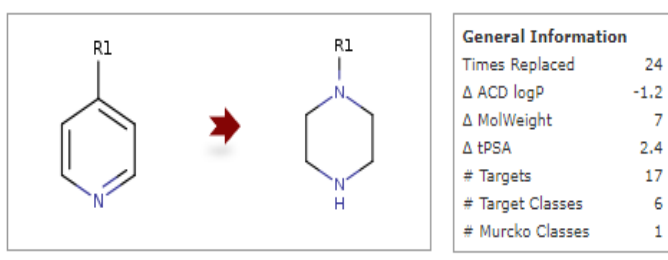

\# Murcko Class

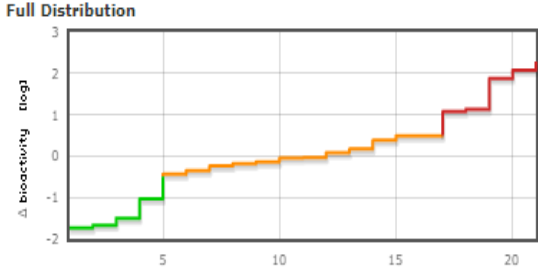

entry number
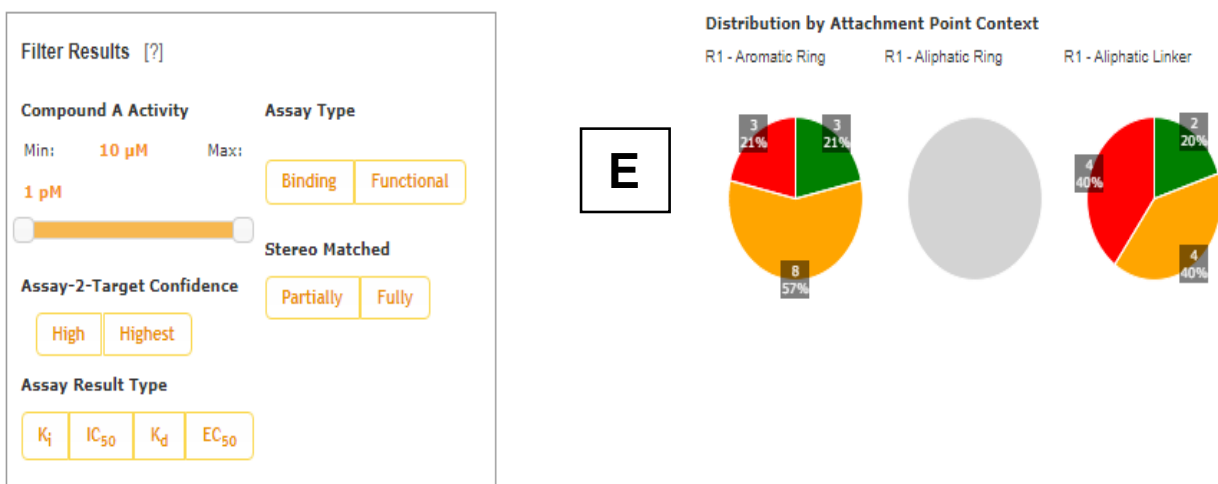

Figure 15. Exploring the influence of bioisosteric replacements on the main scaffold of Ciclopirox: (A) Scheme for study; (B) tetrahydro-2H-pyranbioisosteres; (C) Piperidine bioisosteres; (D) Morpholine bioisosteres; (E)

Piperazine bioisosteres.

As a result, we performed molecular docking and virtual screening of CPX against six key cancer target proteins. Based on the docking tools, we discovered that the ligand had low binding energy (potentially high inhibitory activity) against all cancer targets and had low rootmean-square deviation values. Our findings pointed to six new protein-ligand dockings with reduced binding energies as possible cancer inhibitors. Our docking results showed low binding energy for Catenin $\beta-1(-4.90 \mathrm{kcal} / \mathrm{mol})$ as compared to other targets. The Retinoblastoma protein and Protein deglycase DJ-1 $(-5.50 \mathrm{kcal} / \mathrm{mol}$ and $-5.22 \mathrm{kcal} / \mathrm{mol})$ respectively compared with Cyclin-dependent kinase $4(-6.25 \mathrm{kcal} / \mathrm{mol})$, High-mobility group AT-hook 2 (-6.61 $\mathrm{kcal} / \mathrm{mol})$ and $\mathrm{Cdc} 25 \mathrm{~A}(-4.96 \mathrm{kcal} / \mathrm{mol})$.

All docking energy was identified as a possible inhibitor in our investigation, which is consistent with prior molecular docking investigations. OPL, also known as Eloxatin, a drug used in cancer treatment to treat colorectal cancer, was found to have a similar binding energy value withCdc25A protein as that of CPX [25]. OPL binds to Cdc25A(-6.63 kcal $/ \mathrm{mol})$, Catenin $\beta-1(-6.02 \mathrm{kcal} / \mathrm{mol})$, Retinoblastoma protein $(-6.42 \mathrm{kcal} / \mathrm{mol})$, Protein deglycase DJ-1 (-4.85 $\mathrm{kcal} / \mathrm{mol})$, Cyclin-dependent kinase $4(-5.79 \mathrm{kcal} / \mathrm{mol})$, and High-mobility group AT-hook 2 ($7.71 \mathrm{kcal} / \mathrm{mol}$ ), which is the almost matching with CPX. CPX presented a better inhibitory perspective than OPL against two targets, DJ-1 and p-CDK4, with a docking score difference of less than $1 \mathrm{Kcal} / \mathrm{mol}$. OPL and CPX have different amino acid interactions because their structure, molecular weight, and formula are different. CPX was discovered to have high inhibitory activity on cancer-related proteins in recent research, most likely due to a mechanism of altering interaction [26].

Drug repurposing, also known as drug repositioning, is the practice of repurposing already approved medicines for new medicinal use. The medication research approach was already gaining traction before COVID-19's promise was disclosed to the public. Traditionally, it takes 12 to 15 years to find and put a new medicine to market, with a budget of $\$ 1$ billion to $\$ 2$ billion. Existing data on how a medication may be used, including safety and toxicity data, lower the requirement for early stages of drug development, such as safety studies. Drug repurposing has the potential to save both time and costs. According to certain research, the 
time to market may be cut in half and the expenses even lower while lowering the chance of failure. The idea of reusing CPX is not new, and there are a few instances in standard databases.

CPX has been discovered to allosterically stabilize a mutant biosynthetic enzyme (uroporphyrinogen-III synthase or UROIIIS) that causes congenital erythropoietic porphyria according to a recent study. In a mouse model of porphyria, oral treatment enhanced UROIIIS activity and decreased clinical symptoms. The medication repurposing process may be used to explore treatments for additional metabolic disease-causing enzyme mutations [27]. This offpatent antifungal medication has also been identified as a potential antibiotic repurposing option for drug-resistant Escherichia coli, Acinetobacter baumannii, and Klebsiella pneumoniae [28]. In a recent study, CPX was shown to have virulence-modifying properties against clinical isolates of Multidrug-Resistant Pseudomonas aeruginosa [29]. This fungicide (used to treat skin and nail mycoses) has been repurposed to mediate anticancer action by reducing cell proliferation and causing apoptosis in solid tumor cells such as breast carcinoma (MDA-MB231) and human rhabdomyosarcoma (Rh30). CPX reduced cell proliferation by halting cells in the $\mathrm{G}_{1} / \mathrm{G}_{0}$ phase of the cell cycle, which is linked to CDK inhibition, resulting in hypophosphorylation of the retinoblastoma $(\mathrm{Rb})$ protein. CPX promoted apoptosis by decreasing Bcl-xL and survivin expression while boosting Bcl-2 cleavage. In addition, in an in vitro model, CPX reduced lymphangiogenesis (tube formation). Overexpression of VEGFR-3 provided partial resistance to the CPX inhibitory impact on tube formation in lymphatic endothelial cells [30], and this effect was linked to suppression of VEGFR-3 expression. In recent years, the function of CPX in suppressing the Herpes simplex virus (HSV)-1 and HSV2 has been documented. HSV-1 infection of the peripheral nerve system, both acute and latent, was substantially decreased by the medication [31]. The use of CPX as an anti-ischemic stroke drug has just been reported. A single dosage of CPX administered post-ischemic produced a long-lasting neuroprotective effect, which was increased by repeated doses of CPX administration [32]. The preventive efficacy of CPX against ovariectomy-induced bone loss in mice was investigated recently, and its repurposing possibilities against postmenopausal osteoporosis were considered [33]. In a mouse dermatitis model, CPX decreased inflammatory cell recruitment, ear swelling, and poly(ADP-ribosyl)ation, indicating that its $\mathrm{Fe}^{2+}$ chelation and indirect PARP inhibitory activities contribute to anti-inflammatory benefits [34]. The repurposing of CPX for CRC has brought up new pharmacotherapeutic possibilities. By altering Snail, N-cadherin, MMP-2, E-cadherin, and MMP-9 expression, CPX induced cell cycle arrest, repressed cell migration, and invasion in CRC.The CPX-induced inhibition of cell growth, migration, and invasion was due to a breakdown of cellular bioenergetics. [35].CPX has been identified as a novel potent inhibitor of HMGA2. Furthermore, by direct contact with the AT-hook motif (a tiny DNA-binding protein motif) of HMGA2, CPX causes cytotoxicity in CRC cells by inducing cell cycle arrest and death in vitro and in vivo. [36]. In vitro and in vivo studies showed that CPX reduced CRC development by reducing proliferation and induced apoptosis. Downregulation of DJ-1 was implicated in CPX's anticancer actions, and overexpression of DJ-1 may counteract CPX's cytotoxic impact on CRC cells [16].

Because of its (CPX) ability to inhibit a large number of targets such as enzyme, hydrolase, protease, a nuclear protein, ligand-gated ion channel, voltage-gated ion channel, oxidoreductase, kinase, primary active transporter, electrochemical transporter, family A-G protein-coupled receptor, and family A-G protein-coupled receptor, repurposing this antifungal drug CPX against new cancer targets will be an imperative decision [37]. The prediction for inhibition of enzymes [Cell division cycle 25A (Cdc25A) and Cyclin-dependent kinase-4 
(CDK4)] and protein targets [Protein deglycase DJ-1 (DJ-1), Catenin $\beta-1$ (Wnt/-catenin), Retinoblastoma protein (p-Rb/Rb), and High-mobility group AT-hook-2 (HMGA2)] by CPX against CRC holds true in molecular docking studies.

CPX is quickly absorbed after oral treatment and fully removed in all species through feces and urine, according to pharmacokinetic studies in animals and humans. The majority of the chemical is eliminated as glucuronide or unaltered. Within 12 hours of giving $10 \mathrm{mg}$ of radiolabeled medication to healthy volunteers, about 96 percent of the radioactivity was eliminated through renal excretion. Glucuronides made up 94 percent of the radioactivity discharged by the kidneys. This compound's primary metabolic route is glucuronidation. At two weeks, one, two, four, and six months after the start of therapy and four weeks after the end of treatment, random blood concentrations and urine excretion of CPX were measured. CPX serum levels in this research varied from 12-80 $\mathrm{ng} / \mathrm{mL}$. The average absorption of CPX from the dosage form was $5 \%$ of the administered dose, according to urine data. CPX levels in serum and urine were below the detection limit one month after treatment ended [38]. These data supported that the drug is non-toxic, has proper absorption, demonstrates optimal distribution, fairly high bioavailability, and excretion characteristics.

\section{Conclusions}

This in silico study suggests re-utilization of an antifungal drug component Ciclopirox for treating colorectal cancer by inhibiting some of the prominent molecular targets such as Cell division cycle 25A (Cdc25A), Protein deglycase DJ-1 (DJ-1), Retinoblastoma protein (p$\mathrm{Rb} / \mathrm{Rb}$ ), Cyclin-dependent kinase 4 (p-CDK4), High-mobility group AT-hook 2 (HMGA2), and Catenin beta-1 (Wnt/ $\beta$-catenin). The compound demonstrated the best inhibition against HMGA 2 with a docking score of $-6.62 \mathrm{Kcal} / \mathrm{mol}$, nearly comparable with the inhibitory profile of oxaliplatin (docking score of $-7.71 \mathrm{Kcal} / \mathrm{mol}$ ). Ciclopirox presented a better inhibitory perspective than oxaliplatin against two targets, DJ-1 and p-CDK4, with a docking score difference of less than $1 \mathrm{Kcal} / \mathrm{mol}$. In silico pharmacokinetic studies, target prediction studies against 3 species, and bioisosteric-based studies using online tools (SwissADME, SwissTargetPrediction, and SwissBioisostere) also supported the possibilities of leadership development. The study will open new avenues of application of this antifungal drug for clinicians, chemists, and other scientific professionals in context to emerging cancer challenges through a simple repurposing strategy.

\section{Funding}

This research received no external funding.

\section{Acknowledgments}

None acknowledged.

\section{Conflicts of Interest}

The authors declare no conflict of interest. 


\section{References}

1. Kolligs, F.T. Diagnostics and epidemiology of colorectal cancer. Visceral Med. 2016, 32,158-64, https://doi.org/10.1159/000446488.

2. Marley, A.R.; Nan, H. Epidemiology of colorectal cancer. Int J Mol Epidemiol Genet. 2016, 7, 105-14, https://www.ncbi.nlm.nih.gov/pmc/articles/PMC5069274/.

3. Rawla P.; Sunkara T.; Barsouk A. Epidemiology of colorectal cancer: incidence, mortality, survival, and risk factors. Przegladgastroenterologiczny. 2019, 14, 89-103,https://doi.org/10.5114/pg.2018.81072.

4. Xie Y.H.; Chen Y.X.; Fang J.Y. Comprehensive review of targeted therapy for colorectal cancer. Signal Transd Targ Ther. 2020, 5, 1-30, https://doi.org/10.1038/s41392-020-0116-Z.

5. Lichtenstern C.R.; Ngu R.K.; Shalapour S.; Karin M. Immunotherapy, inflammation and colorectal cancer. Cells. 2020, 9, 618, https://doi.org/10.3390/cells9030618.

6. Golshani, G; Zhang, Y. Advances in immunotherapy for colorectal cancer: a review. Ther Adv Gastroenterol. 2020, 13, https://doi.org/10.1177/1756284820917527.

7. Haraldsdottir, S.; Einarsdottir, H.M.; Smaradottir, A.; Gunnlaugsson, A.; Halfdanarson, T.R. Colorectal cancer-review. Laeknabladid. 2014, 100, 75-82, https://doi.org/10.17992/lbl.2014.02.531.

8. Gustavsson B.; Carlsson G.; Machover D.; Petrelli N.; Roth A.; Schmoll H.J.; Tveit K.M.; Gibson F. A review of the evolution of systemic chemotherapy in the management of colorectal cancer. Clin Colorectal Cancer. 2015, 14, 1-10, https://doi.org/10.1016/j.clcc.2014.11.002.

9. Favoriti P.; Carbone G.; Greco M.; Pirozzi F.; Pirozzi R.E.; Corcione F. Worldwide burden of colorectal cancer: a review. Update Surg. 2016, 68, 7-11, https://doi.org/10.1007/s13304-016-0359-y.

10. Xie, Y.H.; Chen, Y.X.; Fang, J.Y. Comprehensive review of targeted therapy for colorectal cancer. Signal TransdTargTher. 2020, 5, 1-30, https://doi.org/10.1038/s41392-020-0116-z.

11. Subissi, A.; Monti, D.; Togni, G.; Mailland, F. Ciclopirox. Drugs. 2010, 70, 2133-52, https://doi.org/10.2165/11538110-000000000-00000.

12. Sonthalia, S.; Agrawal, M.; Sehgal, V.N. Topical ciclopirox olamine 1\%: Revisiting a unique antifungal. Indian Dermatol Online J. 2019, 10, 481-5, https://doi.org/10.4103/idoj.IDOJ_29_19

13. Minden, M.D.; Hogge, D.E.; Weir, S.J.; Kasper, J.; Webster, D.A.; Patton, L.; Jitkova, Y.; Hurren, R.; Gronda, M.; Goard, C.A.; Rajewski, L.G. Oral ciclopirox olamine displays biological activity in a phase I study in patients with advanced hematologic malignancies. Am J Hematol. 2014, 89, 363-8, https://doi.org/10.1002/ajh.23640

14. Shen, T.; Shang, C.; Zhou, H.; Luo, Y.; Barzegar, M.; Odaka, Y.; Wu, Y.; Huang, S. Ciclopirox inhibits cancer cell proliferation by suppression of Cdc25A. Genes Cancer. 2017, 8, 505, https://doi.org/10.18632/genesandcancer.135.

15. Huang, Y.M.; Cheng, C.H.; Pan, S.L.; Yang, P.M.; Lin, D.Y.; Lee, K.H. Gene expression signature-based approach identifies antifungal drug ciclopirox as a novel inhibitor of HMGA2 in colorectal cancer. Biomolecules. 2019, 9, 688, https://doi.org/10.3390/biom9110688.

16. Zhou, J.; Zhang, L.; Wang, M.; Zhou, L.; Feng, X.; Yu, L.; Lan, J.; Gao, W.; Zhang, C.; Bu, Y.; Huang, C. CPX targeting DJ-1 triggers ROS-induced cell death and protective autophagy in colorectal cancer. Theranostics. 2019, 9, 5577-94, https://doi.org/10.7150/thno.34663.

17. Guzman, F.; Fazeli, Y.; Khuu, M.; Salcido, K.; Singh, S.; Benavente, C.A. Retinoblastoma tumor suppressor protein roles in epigenetic regulation. Cancers. 2020, 12, 2807, https://doi.org/10.3390/cancers12102807.

18. Lukasik, P.; Załuski, M.; Gutowska, I. Cyclin-Dependent Kinases (CDK) and Their Role in Diseases Development-Review. Int J Mol Sci. 2021, 22, 2935, https://doi.org/10.3390/ijms22062935.

19. Mahapatra, D.K.; Bharti, S.K.; Asati, V. Anti-cancer chalcones: Structural and molecular target perspectives. Eur J Med Chem. 2015, 98, 69-114, https://doi.org/10.1016/j.ejmech.2015.05.004.

20. Chhajed, S.S.; Chaskar, S.; Kshirsagar, S.K.; Haldar, G.A.; Mahapatra, D.K. Rational design and synthesis of some PPAR- $\gamma$ agonists: substituted benzylideneamino-benzylidene-thiazolidine-2,4-diones. Comp Biol Chem. 2017, 67, 260-5, https://doi.org/10.1016/j.compbiolchem.2017.02.004.

21. Karmakar, B.; Talukdar, P.; Talapatra, S.N. An in silico study for two anti-inflammatory flavonoids of Nerium oleander on proinflammatory receptors. Res J Life Sci Bioinformat Pharm Chem Sci. 2019, 5, 58296, https://doi.org/10.26479/2019.0501.49.

22. Daina, A.; Michielin, O.; Zoete, V. SwissTargetPrediction: updated data and new features for efficient prediction of protein targets of small molecules. Nucleic Acids Res. 2019, 47, W357-64, https://doi.org/10.1093/nar/gkz382. 
23. Wirth, M.; Zoete, V.; Michielin, O.; Sauer W.H. SwissBioisostere: a database of molecular replacements for ligand design. Nucleic acids Res. 2013, 41, D1137-43, https://doi.org/10.1093/nar/gks1059.

24. Mahapatra, D.K.; Bharti, S.K. Handbook of Research on Medicinal Chemistry: Innovations and Methodologies, 1st ed.; Apple Academic Press: New Jersey, USA, 2017; pp. 165-69, https://books.google.ro/books?hl=en\&lr=\&id=doY_DwAAQBAJ\&oi=fnd\&pg=PT7\&dq=Handbook+of +R esearch+on+Medicinal+Chemistry:+Innovations+and+Methodologies,+1st+ed.\%3B+Apple+Academic+Pre ss:+New+Jersey,+Canada,\&ots=KhZvsm5sFy\&sig=BV8q_KdHDZc5xPVKqlH0c-

XIn5w\&redir_esc=y\#v=onepage\&q\&f=false.

25. Karlsson, H.; Senkowski, W.; Fryknäs, M.; Mansoori, S.; Linder, S.; Gullbo, J.; Larsson, R.; Nygren, P. A novel tumor spheroid model identifies selective enhancement of radiation by an inhibitor of oxidative phosphorylation. Oncotarget. 2019, 10, 5372-82, https://doi.org/10.18632/oncotarget.27166.

26. Zhou, H.; Shen, T.; Luo, Y.; Liu, L.; Chen, W.; Xu, B.; Han, X.; Pang, J.; Rivera, C.A.; Huang, S. The antitumor activity of the fungicide ciclopirox. Int $J$ Cancer. 2010, 127, 2467-77, https://doi.org/10.1002/ijc.25255.

27. Urquiza, P.; Laín, A.; Sanz-Parra, A.; Moreno, J.; Bernardo-Seisdedos, G.; Dubus, P.; González, E.; Gutiérrez-de-Juan, V.; García, S.; Eraña, H.; San Juan, I. Repurposing ciclopirox as a pharmacological chaperone in a model of congenital erythropoietic porphyria. Sci Transl Med. 2018, 10, 4247,https://doi.org/10.1126/scitranslmed.aat7467.

28. Carlson-Banning, K.M.; Chou, A.; Liu, Z.; Hamill, R.J.; Song, Y.; Zechiedrich L. Toward repurposing ciclopirox as an antibiotic against drug-resistant Acinetobacter baumannii, Escherichia coli, and Klebsiella pneumoniae. PloSOne. 2013, 8, e69646, https://doi.org/10.1371/journal.pone.0069646.

29. Zakaria, A.S.; Edward, E.A.; Mohamed, N.M. Evaluation of Ciclopirox as a Virulence-modifying Agent Against Multidrug Resistant Pseudomonas aeruginosa Clinical Isolates from Egypt. Microbiol Biotechnol Lett. 2019, 47, 651-61, https://doi.org/10.4014/mbl.1908.08002

30. Huang, S. Repurposing the fungicide ciclopirox olamine for cancer therapy. International Conference and Exhibition on Biochemical \& Molecular Engineering. October 07-08, 2013 Hilton San Antonio Airport, TX, USA.

31. Bernier, K.M.; Morrison L.A. Antifungal drug ciclopirox olamine reduces HSV-1 replication and disease in mice. Antiviral Res. 2018, 156, 102-6, https://doi.org/10.1016/j.antiviral.2018.06.010.

32. Feng, H.; Hu, L.; Zhu, H.; Tao, L.; Wu, L.; Zhao, Q.; Gao, Y.; Gong, Q.; Mao, F.; Li, X.; Zhou, H. Repurposing antimycotic ciclopirox olamine as a promising anti-ischemic stroke agent. Acta Pharm Sinica B. 2020, 10, 434-46, https://doi.org/10.1016/j.apsb.2019.08.002.

33. Ihn H.J.; Lim J.; Kim K.; Nam S.H.; Lim S.; Lee S.J.; Bae J.S.; Kim T.H.; Kim J.E.; Baek M.C.; Bae Y.C. Protective Effect of Ciclopirox against Ovariectomy-Induced Bone Loss in Mice by Suppressing Osteoclast Formation and Function. Int J Mol Sci. 2021, 22, 8299, https://doi.org/10.3390/ijms22158299.

34. Regdon, Z.; Demény, M.A.; Kovács, K.; Hajnády, Z.; Nagy-Pénzes, M.; Bakondi, E.; Kiss, A.; Hegedűs, C.; Virág, L. High-Content Screening identifies inhibitors of oxidative stress-induced parthanatos: cytoprotective and anti-inflammatory effects of ciclopirox. British J Pharmacol. 2021, 178, 1095-113, https://doi.org/10.1111/bph.15344.

35. Qi, J.; Zhou, N.; Li, L.; Mo, S.; Zhou, Y.; Deng, Y.; Chen, T.; Shan, C.; Chen, Q.; Lu, B. Ciclopirox activates PERK-dependent endoplasmic reticulum stress to drive cell death in colorectal cancer. Cell Death Dis. 2020, 11, 1-6, https://doi.org/10.1038/s41419-020-02779-1.

36. Huang, Y.M.; Cheng, C.H.; Pan, S.L.; Yang, P.M.; Lin, D.Y.; Lee, K.H. Gene expression signature-based approach identifies antifungal drug ciclopirox as a novel inhibitor of HMGA2 in colorectal cancer. Biomolecules 2019, 9, 688, https://doi.org/10.3390/biom9110688.

37. Nickel, J.; Gohlke, B.O.; Erehman J.; Banerjee P.; Rong W.W.; Goede A.; Dunkel M.; Preissner R. SuperPred: update on drug classification and target prediction. Nucleic Acids Res. 2014, 42, W26-31, https://doi.org/10.1093/nar/gku477.

38. Lukasova, I.; Muselík, J.; Vetchy, D.; Gajdziok, J.; Gajdosova, M.; Jurica, J.; Knotek, Z.; Hauptman, K.; Jekl, V. Pharmacokinetics of ciclopirox olamine after buccal administration in rabbits. Curr Drug Deliv. 2017, 14, 99-108, https://doi.org/10.2174/1567201813666160502142856. 